\title{
Impact of SMTP Targeting Plasminogen and Soluble Epoxide Hydrolase on Thrombolysis, Inflammation, and Ischemic Stroke
}

\author{
Keiji Hasumi ${ }^{1,2, *(1)}$ and Eriko Suzuki ${ }^{1}$ \\ 1 Department of Applied Biological Science, Tokyo University of Agriculture and Technology, \\ Tokyo 183-8509, Japan; ersuzuki@cc.tuat.ac.jp \\ 2 Division of Research and Development, TMS Co., Ltd., Tokyo 183-0023, Japan \\ * Correspondence: hasumi@cc.tuat.ac.jp; Tel.: +81-42-367-5710
}

check for

updates

Citation: Hasumi, K.; Suzuki, E. Impact of SMTP Targeting Plasminogen and Soluble Epoxide Hydrolase on Thrombolysis, Inflammation, and Ischemic Stroke. Int. J. Mol. Sci. 2021, 22, 954. https://doi.org/10.3390/ijms22020954

Received: 17 December 2020

Accepted: 12 January 2021

Published: 19 January 2021

Publisher's Note: MDPI stays neutral with regard to jurisdictional claims in published maps and institutional affiliations.

Copyright: (c) 2021 by the authors. Licensee MDPI, Basel, Switzerland. This article is an open access article distributed under the terms and conditions of the Creative Commons Attribution (CC BY) license (https:/ / creativecommons.org/licenses/by/ $4.0 /)$

\begin{abstract}
Stachybotrys microspora triprenyl phenol (SMTP) is a large family of small molecules derived from the fungus $S$. microspora. SMTP acts as a zymogen modulator (specifically, plasminogen modulator) that alters plasminogen conformation to enhance its binding to fibrin and subsequent fibrinolysis. Certain SMTP congeners exert anti-inflammatory effects by targeting soluble epoxide hydrolase. SMTP congeners with both plasminogen modulation activity and anti-inflammatory activity ameliorate various aspects of ischemic stroke in rodents and primates. A remarkable feature of SMTP efficacy is the suppression of hemorrhagic transformation, which is exacerbated by conventional thrombolytic treatments. No drug with such properties has been developed yet, and SMTP would be the first to promote thrombolysis but suppress disease-associated bleeding. On the basis of these findings, one SMTP congener is under clinical study and development. This review summarizes the discovery, mechanism of action, pharmacological activities, and development of SMTP.
\end{abstract}

Keywords: SMTP; Stachybotrys microspora; triprenyl phenol; plasminogen; fibrinolysis; thrombolytic; soluble epoxide hydrolase; antioxidative; inflammation; stroke; cerebral infarction

\section{Introduction}

The hemostatic system is finely regulated to achieve continuous blood circulation and prevent blood loss based on the balance between blood coagulation and fibrinolysis (blood clot degradation) [1-3]. The zymogens in this system contribute to autonomous regulation through spatiotemporal activation in response to physiological demands or stimuli [4,5]. Defects in the hemostatic system lead to bleeding or thrombotic disorders [6-9]. To date, several drugs have been developed to treat diseases related to or resulting from such defects in the hemostatic system. Particularly, antithrombotics, which inhibit blood clot formation, and thrombolytics, which accelerate the degradation of blood clots, are widely used to treat, control, or prevent thrombotic complications such as ischemic diseases of the heart, brain, lungs, and kidneys [10-14]. Despite several efforts to elaborate the use of these drugs, a significant population of treated patients suffer from bleeding events, which are occasionally severe or fatal [11,15-17]. Thus, it is believed that antithrombotics and thrombolytics are associated with an inherent inevitable bleeding risk [18].

In 1993, we initiated an investigation to identify a bioactive compound that controls the hemostatic system, particularly a small molecule that promotes endogenous fibrinolysis [4]. Our theory was that a molecule that modulates the physiological process will achieve a therapeutic effect without excessive bleeding risk. Using several systems to screen random microbial metabolites, we discovered multiple compounds with a novel activity, zymogen modulation [4]. Stachybotrys microspora triprenyl phenol (SMTP) is a class of identified compounds that modulate the conformation of plasminogen to promote plasminogen binding to fibrin or the cell surface [4,9]. SMTP is a large family of metabolites from $S$. microspora, comprising more than 60 congeners (Table S1) $[19,20]$. In agreement with our hypothesis, SMTP promotes thrombolysis without causing excessive bleeding [21-24]. 
Subsequently, we observed an unexpected additional function of SMTP, the inhibition of soluble epoxide hydrolase (sEH), which is a key enzyme that controls inflammation [25]. Along with the radical-scavenging activity inherent in the SMTP structure, the combination of thrombolytic and anti-inflammatory actions of SMTP played a key role in the treatment of ischemic stroke in several models of rodents and monkeys [21,22,24,26-30]. One of the SMTP congeners is under clinical development: compound development code, TMS-007; phase 1 study, JapicCTI-142654; and phase 2 study, JapicCTI-183842, registered at the Japan 540 Pharmaceutical Information Center Clinical Trials Information. Here, we review the discovery, mechanism of action, pharmacological activity, and development of SMTP.

\section{Origin of SMTP}

\subsection{Background: Thrombotic and Thromboembolic Disorders and Treatment}

Thrombotic and thromboembolic disorders are ischemic diseases that occur due to vascular occlusion by a blood clot formed in situ (thrombosis) or in an upstream vessel (embolism) that occludes a vessel at a downstream site [18,31,32]. The clot shuts off the supply of blood and oxygen, resulting in the death of the affected tissue. Thrombosis/thromboembolism can occur in both arteries and veins. Arterial thrombosis is the cause of most cases of heart attack (myocardial infarction) and ischemic stroke (brain infarction) [18]. Venous thrombosis/thromboembolism includes deep vein thrombosis, which accounts for most cases of pulmonary embolism (pulmonary infarction) [31]. These cardiovascular diseases constitute the most common causes of death in the developed world.

Atherosclerosis, or the rupture of an atherosclerotic plaque, is one of the most influential triggers for arterial thrombosis $[31,33,34]$. Atherosclerosis develops in the vessel wall through an accumulation of lipid deposits, mediated by macrophage foam cells that accumulate large amounts of cholesterol derived from lipoproteins such as low-density lipoprotein (LDL) that is oxidized in the vessel wall. Upon rupture of an atherosclerotic plaque, platelets rapidly aggregate to form a hemostatic plug through binding to collagen and von Willebrand factor. The aggregated platelets are activated to release several factors that promote the coagulation cascade and platelet aggregation/activation [18].

The coagulation cascade primarily consists of a sequential process of protease zymogen activation that results in the formation of fibrin and thrombus [2]. The exposure of coagulation factor VII to tissue factor, a transmembrane cell surface glycoprotein, is a pathophysiological trigger for the initiation of the coagulation cascade [2]. The hemostatic thrombus can be removed via another cascade reaction, the fibrinolytic system [35]. In both systems, the activation of protease zymogens is a key feature that regulates the local propagation of each event. The regulatory mechanism involves the instant response of the zymogen conformation to pathophysiological stimuli, triggering coagulation and fibrinolysis; the changes in conformation affect the localization and proteolytic activation of zymogens [4].

Generally, drugs targeting platelets (which inhibit platelet aggregation, resulting in the inhibition of blood clot formation) are used to treat arterial thrombosis [36], and venous thrombosis is treated with drugs targeting coagulation cascade proteases [37]. However, agents targeting the coagulation system are increasingly used in arterial disease, as evidenced by the COMPASS trial, where patients with stable atherosclerotic vascular disease were treated with a combination of Xa inhibitor and aspirin [38,39]. Although these drugs treat or prevent arterial and venous thrombosis/thromboembolism, a significant inherent risk of bleeding limits their use [18]. Another important class of drugs used to treat thrombotic/thromboembolic disorders is thrombolytics, such as tissue-type plasminogen activator ( $\mathrm{t}-\mathrm{PA}$ ), which selectively cleaves plasminogen to form plasmin, a protease that degrades fibrin, the major component of blood clots [40]. However, the timing of thrombolytic intervention crucially affects the outcome: the earlier, the better. For example, t-PA therapy is beneficial only when used within 3 to $4.5 \mathrm{~h}$ of ischemic stroke onset, and the risk of intracranial hemorrhage increases significantly when used beyond this time window [41]. Thus, no drug that prevents blood coagulation or promotes thrombolysis 
without causing bleeding has been developed to date. Nevertheless, statins, a class of drugs that lower LDL cholesterol levels and suppress or retard atherosclerosis, are unique in that they reduce the risk of thromboembolic events such as heart attack and ischemic stroke without elevating the risk of bleeding [42]. However, statins do not directly treat thrombotic/thromboembolic diseases.

\subsection{Search for a Bioactive Compound that Enhances Physiological Thrombolysis}

One of the authors (K.H.) was involved in the identification of inhibitors of cholesterol biosynthesis and macrophage foam cell conversion led by Akira Endo, who discovered the first statin drug, ML-236B (compactin), and the second, monacolin K (lovastatin) [42]. Although we discovered several interesting molecules over more than 10 years of research, none of these compounds was developed further. By the early 1990s, several clinical trials had proven the clinical benefit of statin drugs for reducing LDL cholesterol, cardiovascular disease incidence, and mortality [42,43]. Meanwhile, we explored an approach to discover a new drug that directly controls thrombotic/thromboembolic disease through a hitherto unsought mechanism.

The theory behind our investigation was that a compound that enhances plasminogen binding to fibrin or the cell surface would promote physiological fibrinolysis, serving as an ideal approach to achieve regulated thrombus degradation. The basis of this theory was that (i) binding of plasminogen to fibrin or the cell surface is crucial for its activation to plasmin [44]; (ii) lipoprotein(a), a risk factor for cardiovascular diseases and atherosclerosis [45], competes with plasminogen for binding to fibrin and the cell surface [46]; and (iii) regulated fibrinolysis can occur without bleeding. Although this theory has no solid basis, especially regarding whether a small molecule could mediate protein (plasminogen)to-protein (fibrin or receptor) binding, we started a pilot project to search for a molecule that enhances the binding of plasminogen to monocytoid cells (screening 1). Fortunately, a screening of random microbial cultures soon yielded several hits, including complestatin and its analog $[47,48]$. On the basis of these results, we expanded the project to screen for compounds that enhance plasminogen binding to fibrin (screening 2), cell-mediated fibrinolysis in plasma (screening 3), vascular endothelial cell surface generation of plasmin (screening 4), and reciprocal activation of plasminogen and single-chain urokinase-type plasminogen activator (scu-PA or prourokinase) (screening 5). These investigations led to the discovery of novel small molecules such as SMTP family, plactin family, and surfactin family compounds (see Table S1 and references therein). SMTP was discovered in screening 2. Notably, several compounds in these studies act through a unique mechanism, zymogen modulation [4].

\subsection{Discovery of SMTP}

Screening 2 identified several hits. Of these, an extract of a culture of S. microspora IFO 30018 (current repository code NCBI 30018) showed activity to enhance plasminogen-fibrin binding; however, isolation of the active principle was challenging, as the activity was distributed over a wide range of retention times with a turtle shell-like UV absorption peak, according to HPLC analysis. Initially, we believed that the mobile phase conditions were insufficient to achieve clear resolution; however, we subsequently realized that the broad turtle shell-like peak was due to several overlapping peaks with similar UV spectra. Repeated preparative HPLC fractionations corresponding to a relatively sharp convex shape in the turtle shell-like area yielded the first SMTP congener, staplabin (Table S1) [49]. The name staplabin was derived from Stachybotrys plasminogen-binding stimulator. Following the isolation of staplabin, we isolated two minor analogs, SMTP-1 and SMTP-2 (Table S1) [50]. Additionally, we developed a method to isolate multiple congeners by changing the composition of the culture medium to alter the turtle shell-shaped pattern to a truly peaked pattern. To clearly define each anticipated congener that would follow staplabin, we used a new designation, consisting of SMTP and a number. 


\subsection{SMTP Congeners}

The structure of the SMTP congeners consists of a chromanlactam moiety, an isoprene side chain, and a side chain linked to the nitrogen atom of the chromanlactam moiety (N-linked side chain) (Figure 1). Using the newly devised culture conditions mentioned above, we discovered six additional SMTP congeners, SMTP-3 to SMTP-8 (Table S1) [51,52]. These differed with respect to the $N$-linked side chains, all of which constituted known $\alpha$-amino acids. Therefore, we hypothesized that the $N$-linked side chains originated from amino acids present inside the cell or in medium. To test this possibility, we used a poor medium in which amine compounds were restricted but which contained a specific amine to be incorporated as the $N$-linked side chain [53]. This precursor amine-feeding method enabled us to produce large amounts (up to $10 \mathrm{~g} \mathrm{~L}^{-1}$ of culture) of a specific SMTP congener quite selectively. This is a huge achievement, considering that the yield of staplabin was only $24 \mathrm{mg} \mathrm{L}^{-1}$ [49]. Furthermore, selective incorporation of the fed amine into the $\mathrm{N}$-linked side chain was confirmed by the robust incorporation of rare amines such as D-amino acids following feeding [54]. Several SMTP congeners were isolated using a fermentation method that was fed with the precursor amine $[19,20,25,55-59]$ (see Table S1 for details). Furthermore, some analogs differing in the isoprene side chain structure have been identified by microbial conversions of SMTP-0, which has a hydrogen atom as the $N$-linked side chain (Figure 1) [60].

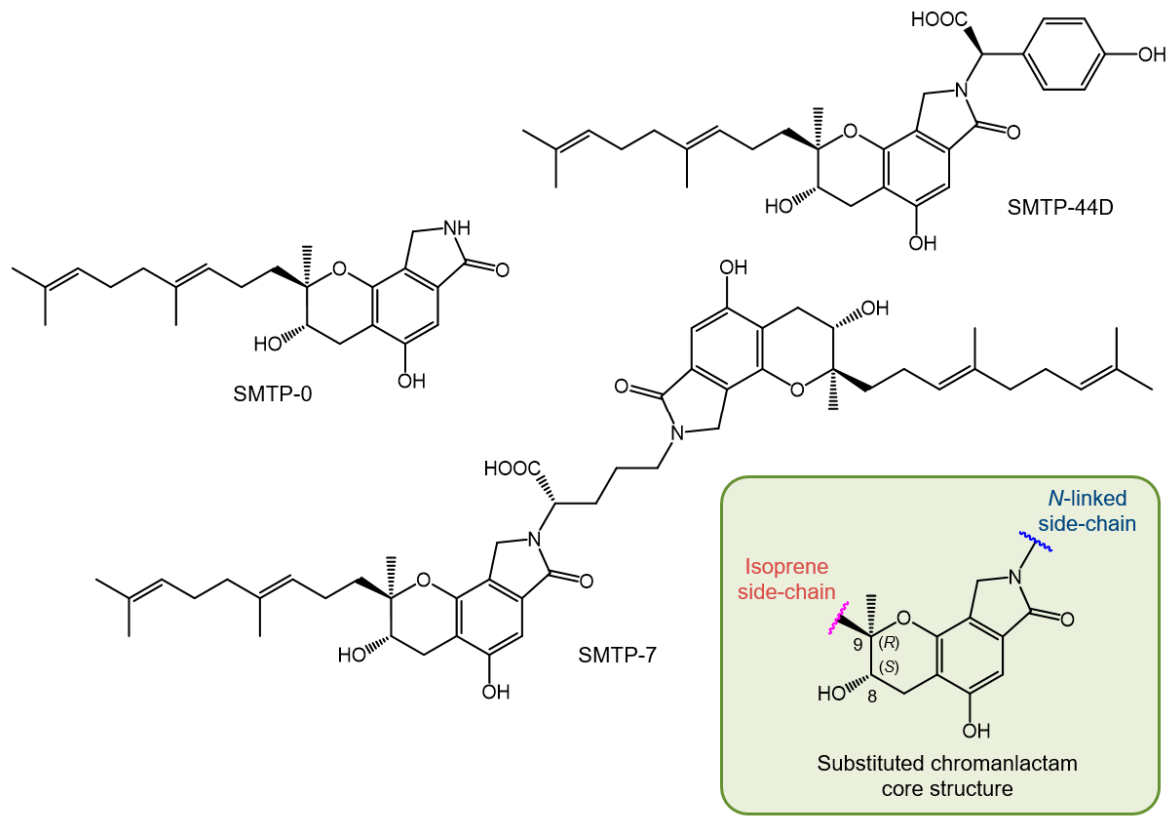

Figure 1. Structures of key Stachybotrys microspora triprenyl phenol (SMTP) congeners and substituted chromanlactam core unit.

\subsection{Structure of SMTP}

The structures of the SMTP congeners were elucidated using a combination of spectroscopic methods, including NMR and MS. The initial absolute stereochemistry was proposed utilizing NMR techniques using the simplest congener, SMTP-0 (Figure 1), and its derivatives [55]. The results obtained were consistent with the $8 S, 9 S$ configuration. However, a recent investigation that utilized a combination of NMR and crystallographic techniques proved an $8 S$, $9 R$ configuration for an analog of SMTP, stachybotrin C (Table S1) [61,62]. Considering that stachybotrin $C$ can be produced by feeding $S$. microspora with the precursor amine and that SMTP is produced from a common precursor, pre-SMTP (see Section 2.6), we conclude that all SMTP congeners exhibit an $8 S, 9 R$ configuration, and herein revise their stereochemistry (Figure 1). 


\subsection{Biosynthesis of SMTP}

To elucidate the mechanism underlying the generation of a wide variety of SMTP congeners, we searched for a biosynthesis precursor of SMTP. We hypothesized that such a precursor might accumulate and disappear before and after amine feeding, respectively. We isolated two candidates: LL-Z1272 $\beta$ (ilicicolin B) and a novel compound. The latter, designated pre-SMTP, has no lactam but two aldehydes in the chroman moiety (Figure 2) [59]. Pre-SMTP spontaneously reacts with primary amines to yield an SMTP congener with the amine as an $N$-linked side chain. Thus, various SMTP congeners can be nonenzymatically derived from pre-SMTP. Incorporating relevant information from other studies [63-65], we propose an overall pathway for SMTP biosynthesis, as presented in Figure 2.

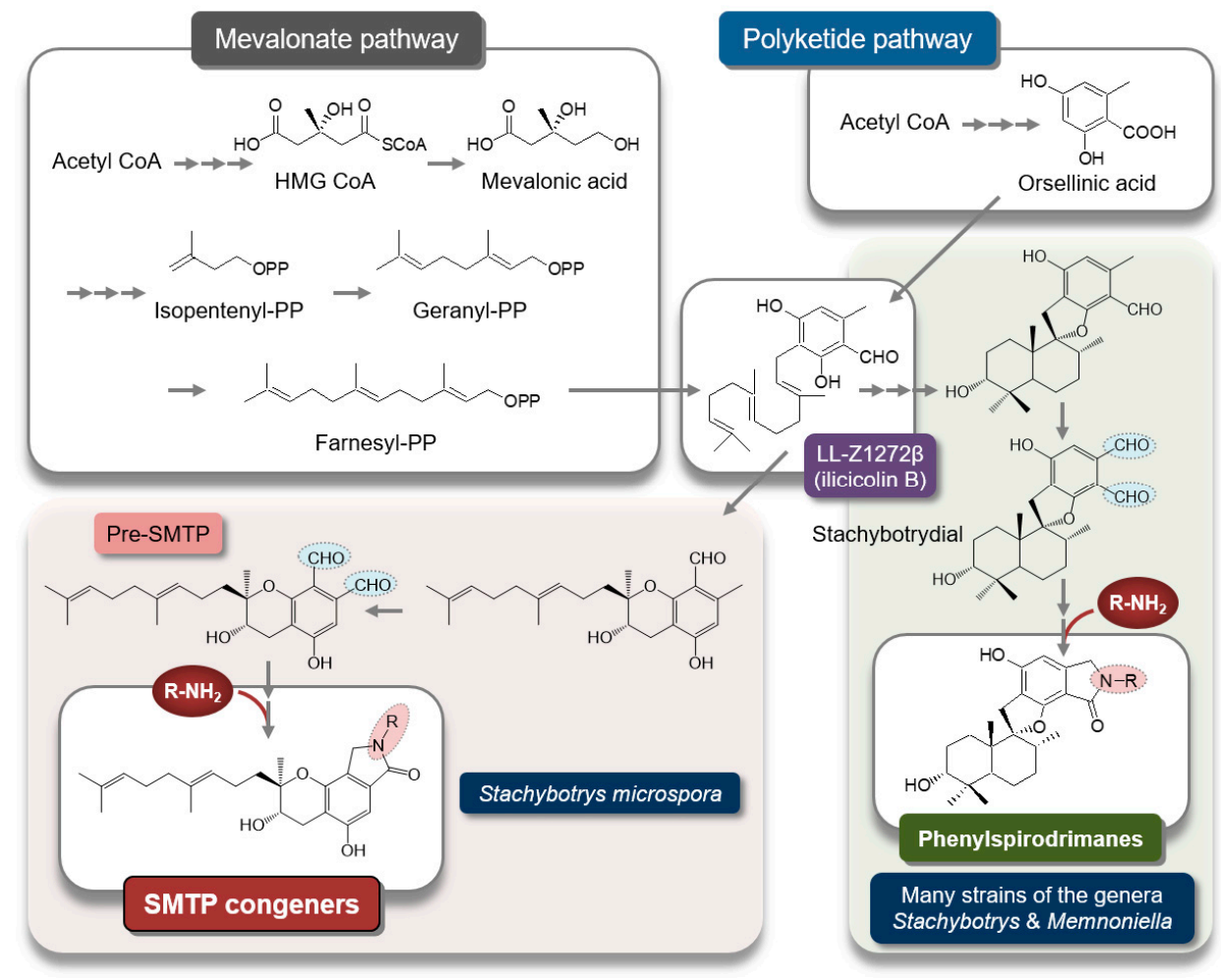

Figure 2. Putative pathway for SMTP biosynthesis. The synthetic pathway for SMTP-type and phenylspirodrimanetype triprenyl phenols may diverge, through differential cyclization mechanisms, from LL-Z1272 $\beta$ (ilicicolin B), a key intermediate synthesized from farnesyl diphosphate and orsellinic acid [63]. Pre-SMTP forms various SMTPs via a nonenzymatic reaction with an amine. Stachybotrydial [66] may yield a wide variety of phenylspirodrimanes via a similar mechanism, because aromatic $o$-dialdehydes (shaded in light blue) are highly reactive with an amine [67,68]. The precursor amine feeding method can be applied to selectively synthesize a phenylspirodrimane of interest [69] using Stachybotrys sp. F462, which forms stachybotramide, a phenylspirodrimane-type triprenyl phenol [70].

\subsection{Other Triprenyl Phenols}

The SMTP congeners belong to a large class of secondary metabolites, called triprenyl phenols, which are characteristic metabolites in the genera Stachybotrys and Memnoniella. Triprenyl phenols exhibit various biological activities depending on their structure [71], such as inhibition of the complement system [72], modulation of cholesteryl ester transfer among lipoproteins [70], antiviral and antiplasmodial activities [73], inhibition of avian myeloblastosis virus protease [74], inhibition of myo-inositol monophosphatase [75], inhibition of fucosyltransferases and syalyltransferases [76], inhibition of cholesterol esterase [77], endothelin-binding antagonism [78], inhibition of receptor tyrosine kinase [79], inhibition of glucose-6-phosphate translocase [80], suppression of lipid accumulation in hepatocytes [81], inhibition of HIV reverse transcriptase [82], antibacterial and antitumor activities [83,84], 
promotion of neurite outgrowth [85], inhibition of farnesyl-protein transferase [86], inhibition of squalene synthase [87], antiviral activity [88], and modulation of plasminogen conformation $[4,89]$, described in detail in the following sections.

\section{Biochemical Actions of SMTP}

\subsection{Enhancement of Plasminogen-Fibrin Binding and Plasminogen Activation}

SMTP and staplabin (hereafter collectively referred to as SMTPs) were discovered through screening for a compound that enhances plasminogen binding to fibrin (see Section 2.2). Additionally, SMTPs promote plasminogen binding to cells. However, it was difficult to postulate that a small molecule could mediate a protein-protein interaction. A key to understanding the mechanism was obtained from the finding that SMTPs promote plasminogen activation to plasmin in the absence of fibrin or cells [90]. Thus, it was conclusive that SMTPs directly act on plasminogen.

To unveil the mechanism of SMTP action, it is essential to understand the conformational regulation of localized plasminogen activation. Circulating human plasminogen (Glu-plasminogen with $\mathrm{Glu}^{1}$ ) is a 791-amino acid single-chain glycoprotein consisting of, from the N-terminus, a plasminogen-apple-nematode (PAN) domain, five homologous kringle domains, and a serine protease domain (Figure 3) [35]. The cleavage at $\mathrm{Arg}^{561}-\mathrm{Val}^{562}$ by t-PA or u-PA forms an active two-chain enzyme, plasmin. Kringles $1,2,4$, and 5 have a lysine-binding site. Kringle 5, unlike other kringles, can bind an internal lysine in addition to a C-terminal lysine. Thus, the kringle 5-lysine binding site is alternatively designated an aminohexyl site [91]. Native Glu-plasminogen adopts a tight conformation that is resistant to activation by plasminogen activators (PAs) (Figure 4). Once Glu-plasminogen binds to fibrin or cell surface receptors, or when it is converted to a truncated form, Lys-plasminogen (with Lys ${ }^{77}$ or Lys ${ }^{78}$ as an N-terminus; see Figure 3), it is readily activated to plasmin by PAs. Alternatively, treatment of Glu-plasminogen with a lysine analog such as tranexamic acid promotes PA-catalyzed activation (see the end of the paragraph for paradoxical antifibrinolytic action of lysine analogs). The common mechanism involved in these apparently different phenomena is the alteration of plasminogen conformation. The tight conformation is due to an intramolecular PAN (Lys $\left.{ }^{50}\right)$-kringle 5 interaction [92,93]. Crystal structure analysis further reveals the involvement of Lys ${ }^{50}$, $\mathrm{Arg}^{68}$, and $\mathrm{Arg}^{70}$ of the PAN domain in the interaction with kringles 4 and $5[94,95]$. The binding of the kringle 5 aminohexyl site and an internal lysine in fibrin (located in D regions and $\alpha \mathrm{C}$-domains) leads to a conformational change in plasminogen, resulting in the formation of a fibrin-plasminogen-t-PA ternary complex that is crucial for the initiation of physiological fibrinolysis [96]. Lys-plasminogen lacks the PAN domain, and hence adopts an open conformation, which facilitates PA-catalyzed activation and fibrin binding. Lysine analogs compete with the lysine residue for the intramolecular PAN-kringle interactions, transforming the plasminogen conformation into an open conformation. Thus, the plasminogen conformation controls its localized activation. It should be noted that lysine analogs are used to block fibrinolysis, even these relax plasminogen conformation. This apparent discrepancy comes from the fact that lysine analogs compete with plasminogen for binding to fibrin (the plasminogen-fibrin binding is indeed mediated by the lysinebinding sites in plasminogen), emphasizing the importance of the plasminogen localization in fibrinolysis [4].

A model that depicts how SMTPs enhance plasminogen-fibrin binding and plasminogen activation was derived from the observations described in the next section. 


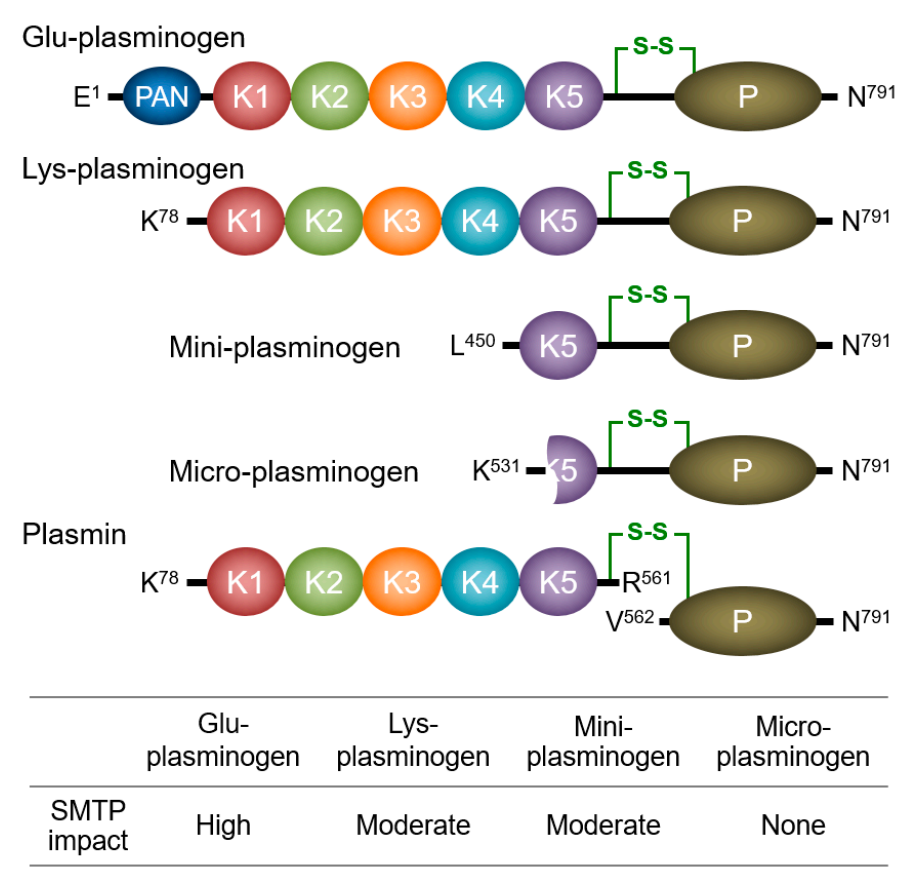

Figure 3. Plasminogen species. Schematic structures of the four plasminogen species and plasmin, and the effect of SMTP-7 on the activation of the four plasminogen species [97] are presented. A key disulfide bond connects the two chains of plasmin (green line). PAN, plasminogen-apple-nematode domain; K, kringle domain; P, protease domain.

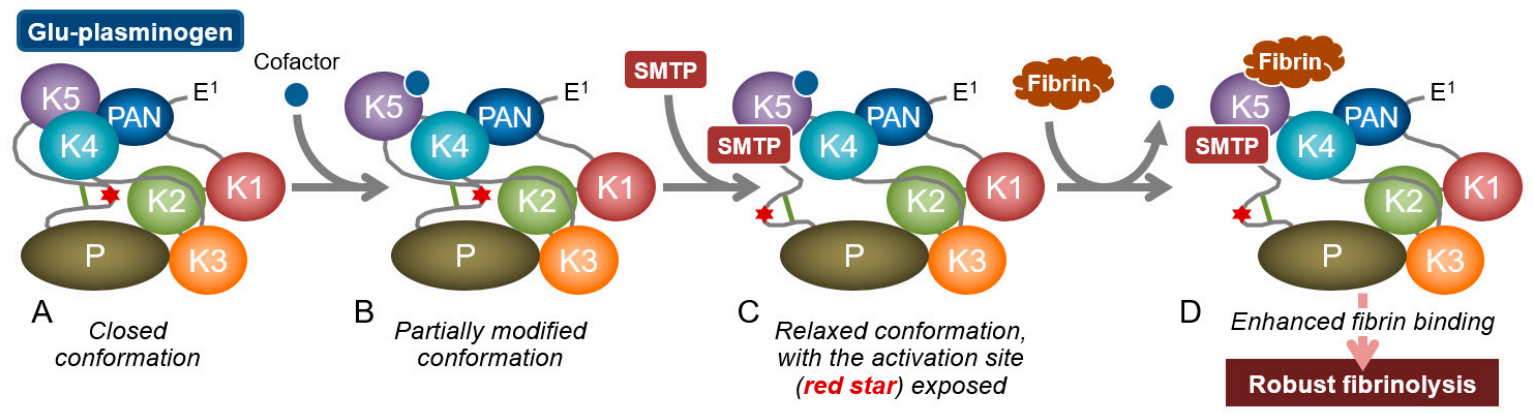

Figure 4. Proposed mechanism for the action of SMTP on plasminogen. (A) Schematic structure of Glu-plasminogen with closed spiral conformation, which is resistant to fibrin binding and plasminogen activator (PA)-catalyzed activation (see Figure 3 legend for designation of the symbol). The image incorporates essential structural information derived from crystallographic studies [94,95]. (B) An SMTP cofactor (phospholipid or unsaturated fatty acid) possibly binds to a site in K5 partly overlapping the aminohexyl site (see [98] for oleic acid-K5 binding) to modify the PAN-K5 interaction (image represents PAN-K5-disrupted molecule). (C) Cofactor-modified conformation may allow SMTP binding (possibly to K5, because SMTP does not affect micro-plasminogen, which lacks intact K5 [97]). SMTP binding leads to large-scale conformational change in plasminogen, enabling (D) robust fibrin binding and PA-catalyzed activation to plasmin (not shown). The resulting plasmin cleaves fibrin to yield C-terminal lysine, to which K1 (as well as K2 and K4) binds strongly, recruiting more plasminogen to accelerate fibrinolysis [99]. Thus, the promotion of plasminogen-fibrin binding and activation of the bound plasminogen in the early phase of fibrinolysis has a significant effect on the subsequent propagation phase. PAN, plasminogen-apple-nematode domain; K, kringle domain; $\mathrm{P}$, protease domain.

\subsection{Modulation of Plasminogen Conformation}

The initial idea for the mechanism of action of the SMTPs $[4,19,90]$ was based on the following observations: (i) SMTPs enhance the fibrin binding of both Glu-plasminogen and Lys-plasminogen; (ii) SMTPs enhance PA-catalyzed activation of both Glu-plasminogen and Lys-plasminogen, with higher enhancement for the former than the latter; (iii) SMTP- 
enhanced Glu-plasminogen activation is largely but not completely abolished in the presence of the lysine analog 6-aminohexanoic acid or a fibrin mimic; (iv) SMTP-enhanced Lys-plasminogen activation is not affected by the lysine analog or fibrin mimic; and (v) in size-exclusion HPLC, the elution of both Glu-plasminogen and Lys-plasminogen is advanced in the presence of SMTPs, representing an increase in the apparent molecular volume of plasminogens. All of these observations are consistent with a model in which SMTPs induce a conformational change in plasminogen [4]. The following additional results [97] enabled us to propose a refined model: (vi) the SMTP action depends on a certain type of surfactant included in the buffer; (vii) phospholipids can be physiologically relevant cofactors; (viii) the cofactor-dependent SMTP effects are obtained with plasminogen molecules containing kringle 5, such as Glu-plasminogen, Lys-plasminogen, and miniplasminogen, but not with micro-plasminogen, which lacks kringle 5 (see Figure 3 for molecular structures of truncated plasminogen species); and (ix) SMTP-promoted plasmin autoproteolysis is observed in Lys-plasmin and mini-plasmin but not micro-plasmin. Thus, kringle 5 is crucial for the action of SMTPs. Among the plasminogen species, the impact of SMTPs on activation is most prominent in Glu-plasminogen, which adopts a tight spiral conformation (Figure 4), supporting the conformational modulation mechanism. Details of the proposed mechanism are shown in Figure 4.

\subsection{Concept of Zymogen Modulation}

In addition to SMTP, several other molecules identified in our studies (Table S2) act by affecting the conformation of zymogen to alter its activation, leading to a comprehensive view that these are zymogen modulators. For example, complestatin [47], thioplabins [100], and stachybotrydial [85] modulate plasminogen conformation [101]. The lipopeptides surfactins/iturins [102,103] and glucosyldiacylglycerol [104] modulate a reciprocal zymogen activation between plasminogen and single-chain u-PA (prourokinase) by altering the conformation of plasminogen (in the case of surfactins/iturins) or single-chain u-PA (in the case of glucosyldiacylglycerol). The cyclic pentapeptide plactins $[105,106]$ affect prothrombin conformation to alter its assembly with factor $\mathrm{Xa}$, factor XIII, and $\mathrm{Ca}^{2+}$ into the prothrombinase complex and the resulting prothrombin activation [107]. Additionally, plactins target a unique protease zymogen, plasma hyaluronan-binding protein (pro-PHBP, or pro-factor VII activating protease; pro-FSAP) to enhance its autocatalytic activation [108]. Details of the zymogen modulation concept are reviewed in [4].

\subsection{Unexpected Anti-Inflammatory Action of SMTP}

In accordance with its mechanism of action, SMTP promotes plasma clot clearance in a pulmonary embolism model $[19,109]$. Nevertheless, we sought additional pathophysiological conditions that might be affected by SMTP. This was because the plasminogen/plasmin system is crucial for pericellular proteolysis, which plays a role in tissue remodeling, wound healing, angiogenesis, embryogenesis, and tumor growth/metastasis [110-112]. SMTP-7 (Figure 1), one of the most active congeners, exhibited significant pharmacological activity in several models. This included the suppression/amelioration of (i) tumor angiogenesis and tumor growth (patents 2 and 4) [109], (ii) hepatitis (patent 5), (iii) nephritis (patent 6), (iv) metabolic disease (patent 13), (v) ulcerative colitis (patent 14) [25], (vi) Crohn's disease (patent 14) [25], (vii) Guillain-Barré syndrome (patent 14) [25], and (viii) cancer cachexia (patent 15). Initially, it was unclear whether the efficacy was derived from something other than the plasminogen-modulating activity, as mentioned above. The development of an SMTP congener, SMTP-44D (Figure 1), which lacks plasminogen-modulation activity [57], clarified this problem. SMTP-44D, as well as SMTP-7, were active in all five models tested (models iv-viii), thus revealing an unexpected activity of SMTP [25]. Inflammation is a pathological basis in most of the abovementioned models. 


\subsection{Soluble Epoxide Hydrolase as an Anti-Inflammatory Target of SMTP}

To elucidate the anti-inflammatory activity of SMTP, we sought to identify a target using another non-plasminogen modulator molecule, SMTP-50, which was immobilized to generate an affinity bead. Affinity purification using mouse liver homogenate, followed by a peptide mass fingerprinting analysis, identified $\mathrm{sEH}$ as a candidate.

In mammals, sEH exists as a homodimer of a two-domain polypeptide, with 555 amino acids in humans [113]. The C-terminal domain exhibits epoxide hydrolase activity (C$\mathrm{EH})$, through which it hydrolyzes anti-inflammatory epoxy fatty acids such as epoxyeicosatrienoic acid (EET) [114,115]. C-EH can be a therapeutic target of several disease states including inflammation, neurological disorders, and pain [116,117]. The N-terminal domain exhibits phosphatase activity (N-phos), through which it hydrolyzes lipophilic phosphomonoesters such as lysophosphatidic acids and sphingosine 1-phosphate [118,119]; however, no consensus has been reached on the physiological role of N-phos [120]. Deletion of sEH and inhibition of C-EH have similar consequences under multiple pathophysiological conditions, including insulin resistance [121], renal disease [122], psychiatric disorders [123], traumatic brain injury [124], atherosclerosis [125], ischemic stroke [126-128], hepatic steatosis [129], inflammatory bowel disease [130], and tissue/organ regeneration [131]. Therefore, it is postulated that most beneficial effects of sEH deficiency are ascribed to the loss of C-EH. Nevertheless, this theory does not negate the role of N-phos.

SMTPs inhibit both C-EH and N-phos activity [25]. C-EH inhibition by SMTP-0 is competitive, and $\mathrm{N}$-phos inhibition is pseudo-noncompetitive. The $\mathrm{C}$-EH-selective inhibitor 12-(3-adamantan-1-yl-ureido) dodecanoic acid (AUDA), which binds to the catalytic pocket, competes with SMTP-0 for binding. Thus, SMTP possibly binds to the C-EH catalytic pocket. The pseudo-noncompetitive mode of N-phos inhibition suggests an allosteric mechanism, whereas SMTP-0 binding to the C-EH pocket does not contribute to N-phos inhibition. Thus, SMTP-0 binds to two distinct sites in sEH.

SMTP can inhibit sEH both in vitro and in vivo, resulting in the decreased formation of dihydroxyeicosatrienoic acid (DHET), an sEH-catalyzed product from EET [25]. In a global analysis of 48 lipid mediators derived from the cyclooxygenase, lipoxygenase, or cytochrome P450 pathways in plasma from Guillain-Barré syndrome model rats, the plasma level of only one out of the 48 metabolites was significantly changed. This particular molecule was 11,12-DHET, which suggests that SMTP exerts a specific effect on the diverse metabolism of signaling lipids [25].

\subsection{Antioxidative Action}

The chroman moiety of SMTP is similar to that of tocopherols, which are potent antioxidants [132]. Therefore, several SMTP congeners exhibit potent antioxidative activity (patent 11) $[57,133]$. Notably, highly active SMTP congeners that have a carboxy- and/or hydroxy-substituted aromatic function in the $N$-linked side chain (see Section 3.7) are potent antioxidants. The antioxidative function contributes to the pharmacological activity of SMTP (see Section 4.2).

\subsection{Structure-Activity Relationship}

The assumption that SMTP binds to two independent sites on the sEH molecule to inhibit C-EH and N-phos implies that some SMTP congeners preferentially bind to either of the sites, resulting in varying selectivity in the inhibition of the two sEH activities, N-phos and C-EH. Indeed, SMTPs with different $N$-linked side chains exhibit varying inhibitory potency toward C-EH and N-phos [25]. Since the difference in the $N$-linked side chain affects the plasminogen modulation activity [56-58], we elucidated the comprehensive structure-activity relationship among plasminogen modulation, N-phos, and C-EH [20].

As presented in Figure 5, the structure of the $N$-linked side chain of SMTP greatly affects its activity toward plasminogen modulation and N-phos/C-EH inhibition. For potent plasminogen modulation, both an aromatic group and a negatively ionizable group are essential as the $\mathrm{N}$-linked side chain. Congeners with a carboxy- and/or hydroxy- 
substituted aromatic function are highly active, while congeners with a hydrophilic function or a highly hydrophobic function are essentially inactive. However, several congeners with a wide variety of $N$-linked side chains inhibit sEH. Notably, SMTP-0, a congener without an $N$-linked side chain, exhibits no plasminogen modulation capacity but potently inhibits both $\mathrm{N}$-phos and C-EH equally. Thus, the core unit (chromanlactam with an isoprene side chain) is sufficient to exert N-phos/C-EH inhibition. Nevertheless, certain congeners with different $N$-linked side chains are considerably less active than SMTP-0, or they preferentially inhibit either $\mathrm{N}$-phos or $\mathrm{C}-\mathrm{EH}$, demonstrating a role for the $N$-linked side chain in altering the potency and selectivity of $\mathrm{sEH}$ inhibition.

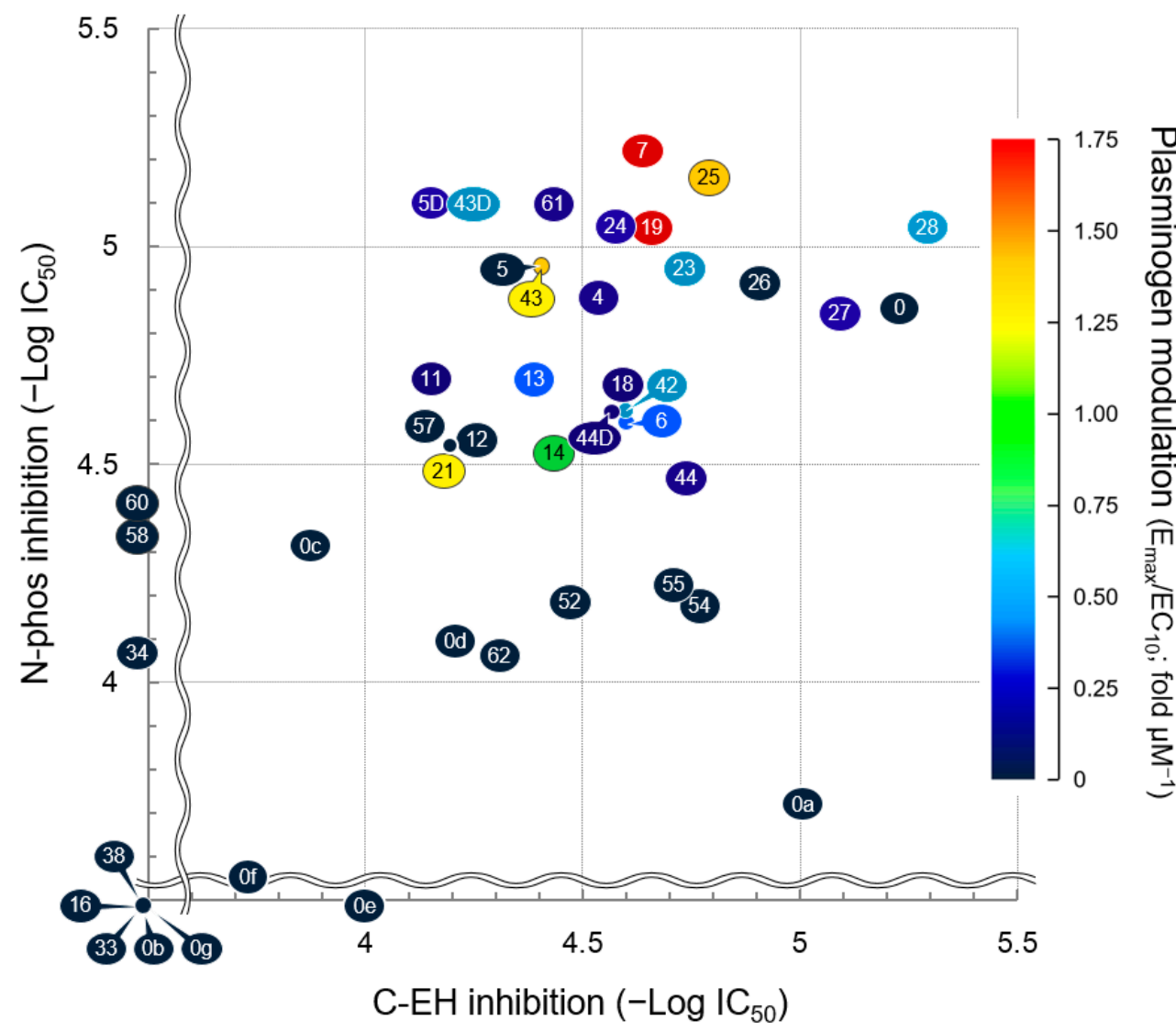

Figure 5. Structure-activity relationships of SMTP congeners with respect to plasminogen modulation and soluble epoxide hydrolase (sEH) inhibition. Plots are based on data in [20,60]. Plot number represents SMTP number (see Table S1 for structure). Details of the dimensions in the three axes are described in [20]. Briefly, the larger the value for each parameter, the stronger the activity (plasminogen modulation or sEH ihibition). C-EH, C-terminal epoxide hydrolase of soluble epoxide hydrolase; N-Phos, N-terminal phosphatase of soluble epoxide hydrolase.

The structural requirement of the $N$-linked side chain for plasminogen modulation and for sEH inhibition are apparently different, as exemplified by SMTP-0. However, certain congeners with a carboxy- and/or hydroxy-substituted aromatic function in the $N$-linked side chain, such as SMTP-7, SMTP-19, SMTP-25, and SMTP-43, are highly active with respect to all three parameters. Since sEH-null mice, which lack both N-phos and $\mathrm{C}-\mathrm{EH}$, are resistant to various disease conditions that primarily involve inflammation [113], simultaneous inhibition of N-phos and C-EH can be an ideal means of pharmacological intervention in such diseases. In ischemic stroke, the combination of plasminogen modulation and sEH inhibition is essential for excellent pharmacological efficacy [29]. Therefore, a congener with all three activities can be a promising drug candidate for ischemic stroke. A congener without plasminogen modulation that inhibits sEH may serve as a potential candidate for targeting inflammatory diseases. 
In addition to the $N$-linked side chain, the isoprene side chain affects sEH inhibitory activity. This conclusion was derived from experiments that evaluated a series of SMTP-0 derivatives isolated after microbial oxidative conversion of the isoprene side chain [60]. All of these derivatives exhibited low N-phos/C-EH inhibitory activity (Figure 5). In addition, analysis of the derivative SMTP-0a revealed an important independent role for the isoprene side chain. The C-EH inhibitory potential of SMTP-0a is approximately 50\% that of SMTP-0, according to a cell-free enzyme assay, whereas the potency of SMTP-0a in a cellular system is only $1 \%$ that of SMTP-0. The fraction of cell-associated SMTP-0a is considerably lower than that of SMTP-0 [60]. Thus, the isoprene side chain contributes to the cellular localization of SMTP.

\section{Pharmacological Activity of SMTP}

While SMTPs have effectively ameliorated various pathological conditions in multiple animal models, as described in Section 3.4, this section focuses on their effect on ischemic stroke. Before describing the pharmacological activity of SMTP, we briefly review the epidemiology and etiology of ischemic stroke, as well as the current status of ischemic stroke treatment.

\subsection{Ischemic Stroke and Treatment Strategy}

Stroke is the second major cause of mortality and a leading cause of long-term disability worldwide $[134,135]$. One-third of stroke cases represent intracerebral or subarachnoid hemorrhage, while two-thirds are cerebral ischemia in 2013 across the world [135]. Ischemic stroke is commonly classified into the following three groups based on clinical manifestations: cardioembolic stroke, atherothrombotic stroke, or lacunar infarction [136]. Cardioembolic stroke, caused by cardiac embolus, accounts for $14-30 \%$ of ischemic stroke cases [137]. Generally, cardioembolic stroke is more severe, and results in a higher mortality rate than other ischemic stroke subtypes [138,139]. Atherothrombotic stroke is caused by an atherosclerotic plaque that narrows the lumen of the artery or occludes the vessel to induce blood clot formation; it accounts for $15-48 \%$ of ischemic stroke cases [140,141]. Infarction by atherothrombotic stroke often progresses in a stepwise fashion. Lacunar infarction is caused by the occlusion of a deep penetrating branch of 2013 a cerebral artery by microatheroma and lipohyalinosis; it accounts for 15-34\% of ischemic stroke cases [141-143]. Typically, the lacunar infarct area is small and the symptoms are relatively mild [144].

Ischemic stroke treatment is classified into two phases, acute phase treatment to rescue penumbra (viable but ischemic tissue) and chronic phase treatment to suppress secondary development of neuronal damage or to promote recovery from damage $[145,146]$. Recanalization therapy, especially thrombolysis and endovascular thrombectomy, is currently the major choice for acute phase treatment [147-149]. Among several thrombolytics developed to date, t-PA (alteplase) is highly recommended for ischemic stroke treatment (see [150-152] for historical and comparative perspectives on the thrombolytics). Despite the robust evidence backing t-PA therapy and endovascular thrombectomy, these therapies are not a panacea; they have some limitations. The use of t-PA is restricted to within $4.5 \mathrm{~h}$ (or $3 \mathrm{~h}$ ) of stroke onset to avoid the deleterious effects of ischemia-reperfusion injury, such as fatal hemorrhagic transformation [153]. Thus, only 3-9\% of patients with ischemic stroke receive t-PA therapy [147]. Endovascular thrombectomy is intended to treat large vessel occlusions [154]. It is estimated that less than $10 \%$ of patients with ischemic stroke qualify for thrombectomy [155], and few stroke centers have sufficient expertise in the procedure [156]. Thus, there is an urgent demand for a new therapy that overcomes these limitations, especially one that can benefit anyone (regardless of disease status) at any time (with a wide time window) and anywhere (regardless of resources/expertise).

\subsection{Efficacy in Embolic Stroke Models}

The first evidence suggesting the effectiveness of SMTP in ischemic stroke was obtained in experiments using a novel embolic stroke model in gerbils [26]. In this model, 
an acetic acid-induced thrombus that formed in the common carotid artery was released to embolize the middle cerebral artery. Following the success in the gerbil model, the same protocol was applied to mice $[21,29,127,157]$. Subsequently, SMTP was tested in another embolic stroke model in cynomolgus monkeys [28]. The observations from these experiments are summarized as follows: (i) SMTP-7 decreases infarct size, neurologic deficits, and edema [21,26,28]; (ii) SMTP-7 exhibits a much wider therapeutic time window than t-PA [21,26]; (iii) t-PA but not SMTP-7 causes intracranial hemorrhage [21]; SMTP-7 increases the level of plasmin- $\alpha_{2}$-antiplasmin complex in the plasma, which reflects plasmin formation in vivo [21,28]; (iv) SMTP-7 progressively restores blood flow, while t-PA causes rapid reperfusion [21]; and (v) SMTP-7 but not t-PA suppresses the expression of inflammatory cytokines in the infarcted brain tissue [21,157].

The structure-activity relationship study reveals some critical features of SMTPs, namely their thrombolytic, anti-inflammatory, and antioxidative activities [29]. A congener in which even one of these three activities is low has limited therapeutic potential in the mouse model of embolic stroke. Thus, the triad is essential for ischemic stroke treatment.

\subsection{Efficacy in Thrombotic Stroke Models}

SMTP-7 has been shown to be effective in thrombotic stroke models in mice [158] and cynomolgus monkeys [22]. In these models, an in situ thrombotic occlusion is induced by photoirradiation at the middle cerebral artery. In summary, SMTP-7 (i) decreases infarct size, neurologic deficits, and edema [22]; (ii) restores blood flow [22,158]; (iii) suppresses hemorrhagic transformation [22]; and (iv) suppresses the expression of inflammatory cytokines in the infarcted brain tissue [158].

\subsection{Efficacy in Mechanical Cerebral Ischemia Models}

In addition to the treatment of thrombotic/thromboembolic brain ischemia, SMTP7 is effective in mechanically induced cerebral ischemia models such as transient and permanent focal ischemia [22]. Since these models do not involve thrombus, the efficacy might be attributable to the anti-inflammatory and/or antioxidative actions of SMTP-7. Indeed, several experiments with transient focal ischemia models demonstrated reduced levels of the following in SMTP-treated animals: (i) reactive oxygen species (ROS) [27,133]; (ii) markers of oxidative damage [24]; (iii) matrix metalloproteinase-9 (MMP-9) and bloodbrain barrier (BBB) disruption [23,27]; (iv) inflammatory cytokines and neuroinflammationrelated proteins [159]; and (v) hemorrhagic transformation [23,24]. Moreover, SMTP-44D, a non-thrombolytic but sEH-inhibitory congener, was shown to reduce oxidative damage markers and protect neurovascular units and trophic coupling from impairment in a mouse model of transient focal ischemia [30].

\subsection{Effects on Bleeding and Hemorrhagic Transformation: Roles for Anti-Inflammatory/Antioxidative Actions}

In normal mice and rats, SMTP-7 only slightly increases the level of plasmin- $\alpha_{2}$ antiplasmin complex, an index of plasmin formation in vivo [19,22], whereas the increase is prominent in embolic stroke models of mice and cynomolgus monkeys [21,28,29]. The difference arises most probably due to the mechanism of action of SMTP: modulation of plasminogen conformation to enhance plasminogen-fibrin binding and subsequent PA-catalyzed plasminogen activation in situ. There may be very few thrombi in normal physiological conditions, and the chance of fibrin/endogenous PA-dependent promotion of plasminogen activation by SMTP can be low under healthy conditions compared to pathological thrombosis conditions. The fibrin/endogenous PA-dependent mechanism may account for the difference in impact between SMTP and pharmacological t-PA on bleeding. t-PA but not SMTP-7 promotes bleeding at pharmacological doses in mice [22]. While pharmacological t-PA can drive plasminogen activation out of the range of the physiological process, as evidenced by the exhaustion of fibrinogen, plasminogen, and $\alpha_{2}-$ antiplasmin [160-162], SMTP only promotes fibrin/endogenous PA-dependent fibrinolysis (Figure 6). Moreover, SMTP-7 does not affect the factors that potentially influence bleeding: 
blood coagulation, platelet activation, heart rate, blood pressure, rectal temperature, and blood physiological parameters [22].

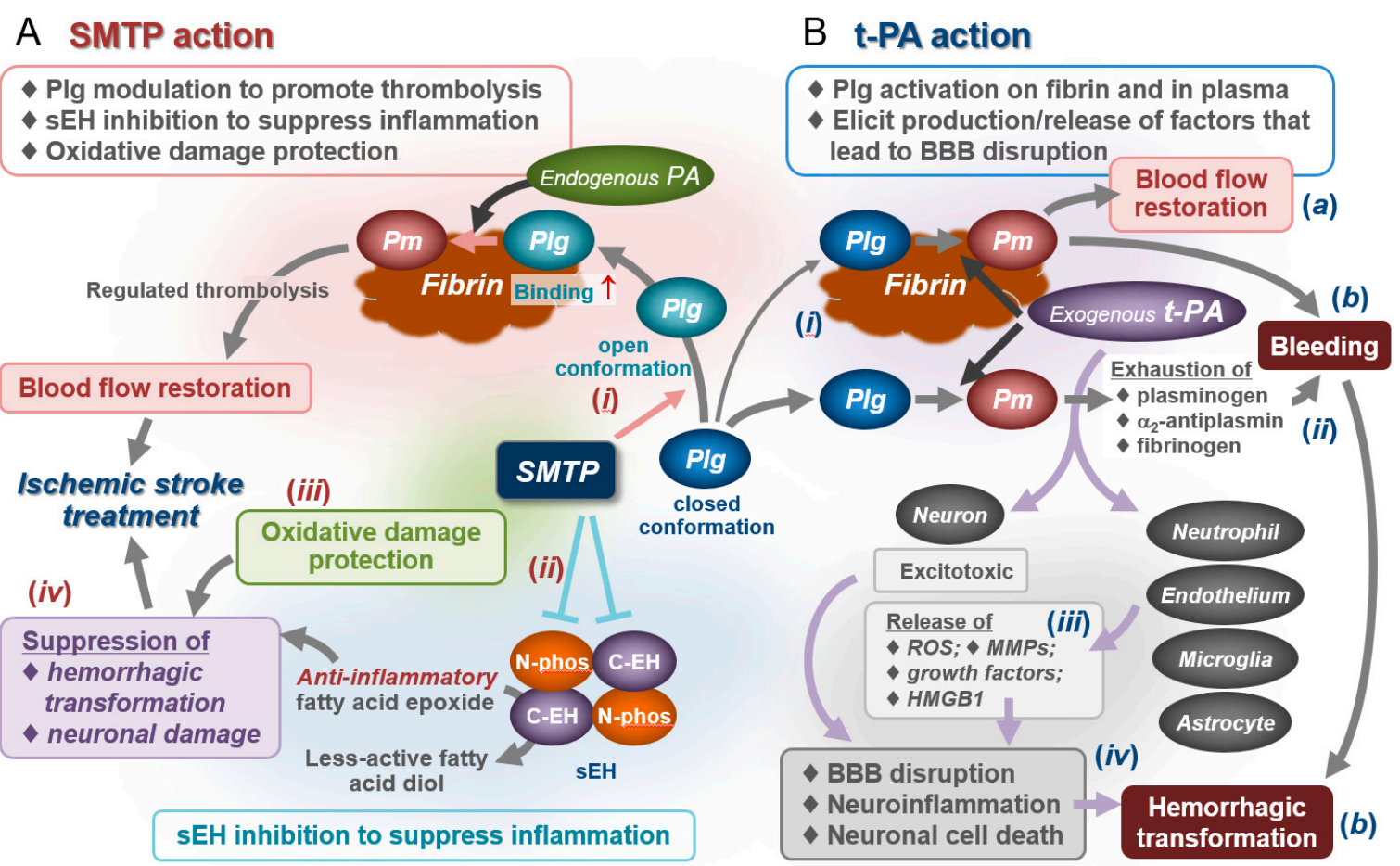

Figure 6. Summary of pharmacological activity of SMTP in comparison with tissue-type plasminogen activator (t-PA). (A) Pharmacological activity of SMTP is derived from a triad of activities: (i) modulation of plasminogen (Plg) conformation, promoting fibrin binding and conversion to plasmin $(P m)$, and subsequent fibrinolysis; (ii) inhibition of sEH, suppressing inflammation; and (iii) antioxidative activity, preventing oxidative damage. Process (i) is dependent on fibrin and endogenous PAs, allowing the SMTP action to promote physiological fibrinolysis. Therefore, pharmacological doses of SMTP do not cause bleeding. In process (ii), inhibition of C-EH-catalyzed hydrolysis of anti-inflammatory epoxy fatty acids such as epoxyeicosatrienoic acid (EET) may play a role; inhibition of N-phos may play an additional role (not shown). In process (iii), radical-scavenging activity inherent in the SMTP structure plays a role in the suppression of oxidative modifications of lipids, proteins, nucleic acids, and sugars [27,30,133,158,159], which are implicated in cytotoxicity, tissue damage, and inflammation. Anti-inflammatory/antioxidative effects contribute to the suppression of neuronal damage and hemorrhagic transformation (iv). SMTP's triad of actions results in an excellent pharmacological effect for ischemic stroke. (B) Tissue-type plasminogen activator (t-PA) therapy is a powerful approach to treat ischemic stroke when administered within $4.5 \mathrm{~h}$ of onset $(a)$; however, clinical outcome is poor when administered beyond this time window $(b)$. t-PA therapy is associated with a significant increase in intracranial hemorrhage $[153,163]$. This can be explained by the following: $(i)$ large amounts of pharmacological t-PA (exogenous t-PA) promote plasminogen activation in fibrin clots and in plasma; (ii) the latter induces the exhaustion of key hemostatic proteins such as plasminogen, $\alpha_{2}$-antiplasmin, and fibrinogen, resulting in increased bleeding risk; (iii) t-PA exhibits non-fibrinolytic action affecting neutrophils, vascular endothelial cells, microglia, and astrocytes to induce production/release of reactive oxygen species (ROS), matrix metalloproteinases (MMPs), growth factors, and high-mobility group box protein 1 (HMGB1), which cause neuronal damage, inflammation, vascular remodeling, and blood-brain barrier (BBB) disruption [163]; and (iv) the systemic bleeding tendency in combination with the non-fibrinolytic action of t-PA increases the risk of hemorrhagic transformation.

Hemorrhagic transformation is a common complication of ischemic stroke [163]. The suppression of hemorrhagic transformation is a remarkable feature of SMTP. This is quite different from the property of t-PA, which increases the risk of bleeding and hemorrhagic transformation [153]. The abovementioned anti-inflammatory/antioxidative mechanisms can contribute to the suppression of ischemia-reperfusion injury, resulting in hemorrhagic transformation. The mechanism involved in the development of early hemorrhagic transformation (within 18-24 h after stroke onset) includes ROS and MMPs (leucocyte-derived 
MMP-9 and brain-derived MMP-2), which damage the neurovascular unit, resulting in disruption of the BBB. Delayed hemorrhagic transformation (>18-24 h) relates to ROS, MMP-2, MMP-3, MMP-9, and t-PA in the brain tissue, as well as neuroinflammation and vascular remodeling factors [163]. SMTPs reduce the levels of (i) inflammatory cytokines, (ii) MMP-9, (iii) ROS and markers of oxidative damage, (iv) neuroinflammation-related proteins, and (v) impairment of the neurovascular unit and trophic coupling; these observations support the theory that SMTP can actively reduce the risk of hemorrhagic transformation (Figure 6).

Thus, SMTP can serve as a drug that promotes recanalization (through enhancement of physiological fibrinolysis) while suppressing hemorrhagic transformation (through anti-inflammatory/antioxidative mechanisms) in ischemic stroke. The difference between SMTP and t-PA in this regard is schematically shown in Figure 6.

\section{Development of SMTP}

On the basis of the abovementioned chemical, biochemical, and pharmacological studies, a potent SMTP congener, TMS-007, is currently under clinical development. This section summarizes the course of the development.

\subsection{Chemistry, Manufacturing, and Controls}

TMS-007 for nonclinical and clinical studies is produced by fermentation using the precursor amine feeding method. Large-scale manufacturing using a fermenter can produce kilogram-order amounts of the TMS-007 drug substance. A formulation that enables the drug infusion has been developed.

In addition to the fermentation method, total synthesis of an SMTP congener has been attempted by certain groups $[164,165]$. Jacolot et al. eventually succeeded in total synthesis of stachybotrin C, an analog of SMTP [61]. However, the synthetic route consists of more than 10 steps, and the overall yield of stachybotrin $C$ from 3,5-dihydroxybenzoic acid is roughly estimated to be less than $3 \%$. The $N$-linked side chain of TMS-007 has additional chiral centers and is structurally more complex than that of stachybotrin $C$, suggesting an advantage of the fermentation method, which has a capacity of several grams per liter, over chemical synthesis production.

\subsection{Nonclinical Studies}

A drug substance manufactured in conformance with the guideline proposed by the International Council for Harmonisation of Technical Requirements for Pharmaceuticals for Human Use was used for nonclinical toxicological and safety assessment under the good laboratory practice guidelines. No serious issues that could hamper future clinical developments were observed in a series of examinations required for a first-in-human study of TMS-007.

\subsection{Phase 1 Clinical Study}

The first-in-human phase 1 clinical study of TMS-007 (registered as JapicCTI-142654 at the Japan Pharmaceutical Information Center Clinical Trials Information) was conducted at the University of Tokyo Hospital, Tokyo, Japan, from October 2014 to August 2015. The design was a randomized, placebo-controlled, double blind, dose-escalation, parallel group study consisting of five cohorts administered different doses $(3,15,60,180$, or $360 \mathrm{mg}$ per individual). The primary objective was to evaluate the safety and tolerability of a single intravenous dose of TMS-007, and the secondary objectives included the characterization of plasma pharmacokinetics and pharmacodynamics. Healthy men aged $20-45$ years were enrolled and randomized 3:1 to receive an intravenous dose of TMS-007 or placebo.

The plasma TMS-007 level was observed to be a linear function of the dose. No symptom of bleeding was found. While safety assessments of t-PA in humans have shown exhaustion of fibrinogen and $\alpha_{2}$-antiplasmin [160-162], these hemostatic factors were not affected by TMS-007 treatment. The plasma level of plasmin- $\alpha_{2}$-antiplasmin complex slightly increased in some of the treated subjects, consistent with nonclinical observations 
in normal animals $[19,22]$. No serious adverse events were observed. Thus, TMS-007 exhibits favorable pharmacokinetic and safety profiles. Details of the phase 1 study will be published elsewhere.

\subsection{Phase 2 Clinical Study}

A randomized, placebo-controlled, double-blind, dose-escalation, parallel group phase 2 study of TMS-007 in patients with acute ischemic stroke was initiated in December 2017 (registered as JapicCTI-183842). This study was aimed at evaluating the safety and efficacy of a single-dose intravenous infusion of TMS-007 in symptomatic patients with ischemic stroke, including cardioembolic and atherothrombotic stroke and lacuna infarction, who were ineligible for t-PA therapy or endovascular thrombectomy. The dose of TMS-007 was set at 1,3 , and $6 \mathrm{mg} \mathrm{kg}^{-1}$. A total of 41 sites were involved in patient enrollment. A draft of the results of this study will be available in 2021.

\section{Conclusions and Perspectives}

More than 60 SMTP congeners have been identified. Several of them exhibit significant plasminogen modulation activity, and many exhibit inhibition of N-phos and/or C-EH of sEH. Of the three portions of the SMTP molecule, the $N$-linked side chain determines the potency and selectivity of action toward plasminogen and sEH. The isoprene side chain mainly contributes to cellular localization. The precursor amine feeding method enables us to selectively produce a large amount of an SMTP congener of interest, thus paving the way for clinical development. A novel concept, zymogen modulation to control its fate, has been derived from a series of explorative studies that led to the discovery of SMTP. SMTP relaxes the conformation of plasminogen to enable the protein to strongly bind to fibrin and promote physiological fibrinolysis without augmenting bleeding. The inhibitory activity of SMTP toward sEH can contribute to its anti-inflammatory activity in vivo. The triad of SMTP activities-plasminogen modulation, anti-inflammatory activity, and antioxidative capacity - is essential for its excellent efficacy in ischemic stroke treatment. A remarkable feature of SMTP efficacy is the suppression of hemorrhagic transformation, which is exacerbated by conventional thrombolytic treatments. No drug with such properties has been developed yet, and SMTP would be the first to promote thrombolysis but suppress disease-associated bleeding. The ongoing phase 2 study will reveal the therapeutic potential of SMTP in patients with ischemic stroke. Moreover, an SMTP congener with both thrombolytic and anti-inflammatory activities can be conceptually effective in the treatment of other thrombotic and thromboembolic diseases such as myocardial infarction and pulmonary embolism. An anti-inflammatory SMTP without thrombolytic power may serve as a drug candidate for the treatment of inflammatory diseases.

\section{Patents}

The following is the list of patents derived from the study of SMTP.

1. Hasumi, K.; Hu, W.; Ohyama, S.; Narasaki, R. Method for Selectively Producing Triprenyl Phenol Compound and Utilization of the Same Compound as Medicine. JP2000306840, filed 31 August 2000.

2. Hasumi, K.; Ohyama, S.; Harada, T.; Hu, W. Plasminogen Fragment Having Neovascularization-Inhibiting Activity and Method for Searching Compound Which Induce Production of the Plasminogen Fragment. JP2001328411, filed 19 September 2001.

3. Hasumi, K.; Hu, W. New Triprenylphenol Compound. JP2003015279, filed 23 January 2003.

4. Hasumi, K.; Hu, W. Medical Composition for Preventing and Treating Angiogenesisassociated Disease. JP2003015279, filed 23 January 2003.

5. Hasumi, K.; Maeda, F.; Mitsumori, K. Agent for Improvement of Hepatic Function. PCT/JP2006/302796, filed 17 February 2006. 
6. Hasumi, K.; Yagasaki, K. Pharmaceutical Composition for Treatment or Prevention of Nephritis and Method for Producing Same. PCT/JP2006/318972, filed 25 September 2006.

7. Hasumi; K.; Nomura, Y.; Narasaki, R.; Tometsuka, C. Skin Aging Inhibitor, Cosmetic and Skin Care Preparation. JP2007036638, filed 16 February 2007.

8. Hasumi, K.; Kitano, Y.; Oish, H.; Koide, H.; Hasegawa, K.; Narasaki, R. Triprenyl Phenol Compound, Process for Production of Triprenyl Phenol Compound, and Thrombolysis Enhancer. PCT/JP2007/055749, filed 20 March 2007.

9. Hasumi, K.; Koide, H.; Narasaki, R. Triprenylphenol Compound and Thrombus Dissolution Accelerator. JP2008060249, filed 10 March 2008.

10. Hasumi, K.; Koide, H.; Narasaki, R. Triprenylphenol Compound and Thrombus Dissolution Accelerator. JP2008060250, filed 10 March 2008.

11. Hasumi, K.; Koide, H.; Hasegawa, K.; Nishimura, N. Antioxidant. JP2010019735, filed 29 January 2010.

12. Honda, K.; Hashimoto, T.; Shibata, K.; Hasegawa, K.; Hasumi, K. Cytoprotective Agent. PCT/JP2010/051711, filed 5 February 2010.

13. Hasumi, K.; Ishikawa, M.; Chikanishi, T.; Nishimura, N.; Hasegawa, K. Pharmaceutical Composition for Metabolic Syndrome, Obesity, Hyperglycemia, Hyperlipidemia and/or Fatty Liver. PCT/JP2010/053545, filed 4 April 2010.

14. Ishikawa, M.; Tanaka, I.; Shirafuji, T.; Hasumi, K. Prophylactic or Therapeutic Agent for Inflammatory Bowel Diseases or Autoimmune Peripheral Neuropathy. PCT/JP2011/058405, filed 1 April 2011.

15. Hasumi, K.; Suzuki, E.; Ogawa, N.; Otake, S.; Kitano, Y.; Hasegawa, K.; Nishimura; N. Soluble Epoxide Hydrolase Inhibitor. PCT/JP2012/054472, filed 23 February 2012.

16. Hasumi, K.; Suzuki, E.; Nishimura, Y.; Kitano, Y.; Hasegawa, K.; Nishimura; N.; Tsujihara, K. Chroman Derivative. PCT/JP2013/055729, filed 1 March 2013.

Supplementary Materials: The following are available online at https://www.mdpi.com/1422-006 7/22/2/954/s1, Table S1: The SMTP congeners, Table S2: The search for bioactive molecules leading to the discovery of the concept of zymogen modulator.

Author Contributions: Conceptualization, K.H.; data curation, K.H. and E.S.; writing—original draft preparation, K.H.; writing — review and editing, K.H. and E.S.; visualization, K.H.; supervision, K.H.; project administration, K.H. and E.S.; funding acquisition, K.H. and E.S. All authors have read and agreed to the published version of the manuscript.

Funding: This research was funded by grants from the Japan Science and Technology Agency (Industry-Academia Joint Innovation Grant H19 to K.H.; https:/ / projectdb.jst.go.jp/grant/JSTPROJECT-11101751 / to K.H.; A-STEP FS stage H21-1 to K.H.; and https:/ / projectdb.jst.go.jp/grant/ JST-PROJECT-7700107485/ to TMS Co.); the New Energy and Industrial Technology Development Organization, Japan (University-Launched Research and Development to Realize Business Creation H17-R\&D-28, R\&D Venture Technology Development Grant H21-2-39, and Translational Research Grant to Small Entity to TMS Co.); the National Federation of Small Business Associations, Japan (H21 grant to TMS Co.); and the Ministry of Education, Culture, Sports, Science and Technology, Japan/Japan Society for the Promotion of Science (10559008 to K.H., 18310143 to K.H., 17 H02201 to KH, 26750362 to E.S., 19 K07118 to E.S., and Translational Research Network Program H26-C to K.H.).

Institutional Review Board Statement: Available in relevant references.

Informed Consent Statement: Available in relevant references or registries.

Data Availability Statement: The data presented in this study are available in this article and supplementary material.

Acknowledgments: The authors thank all the contributors of the original works referred to in this review article for their efforts and Akira Endo for encouragement.

Conflicts of Interest: The authors declare no conflict of interest. The funders had no role in the design of the study; in the collection, analysis, or interpretation of data; in the writing of the manuscript, or in the decision to publish the results. 


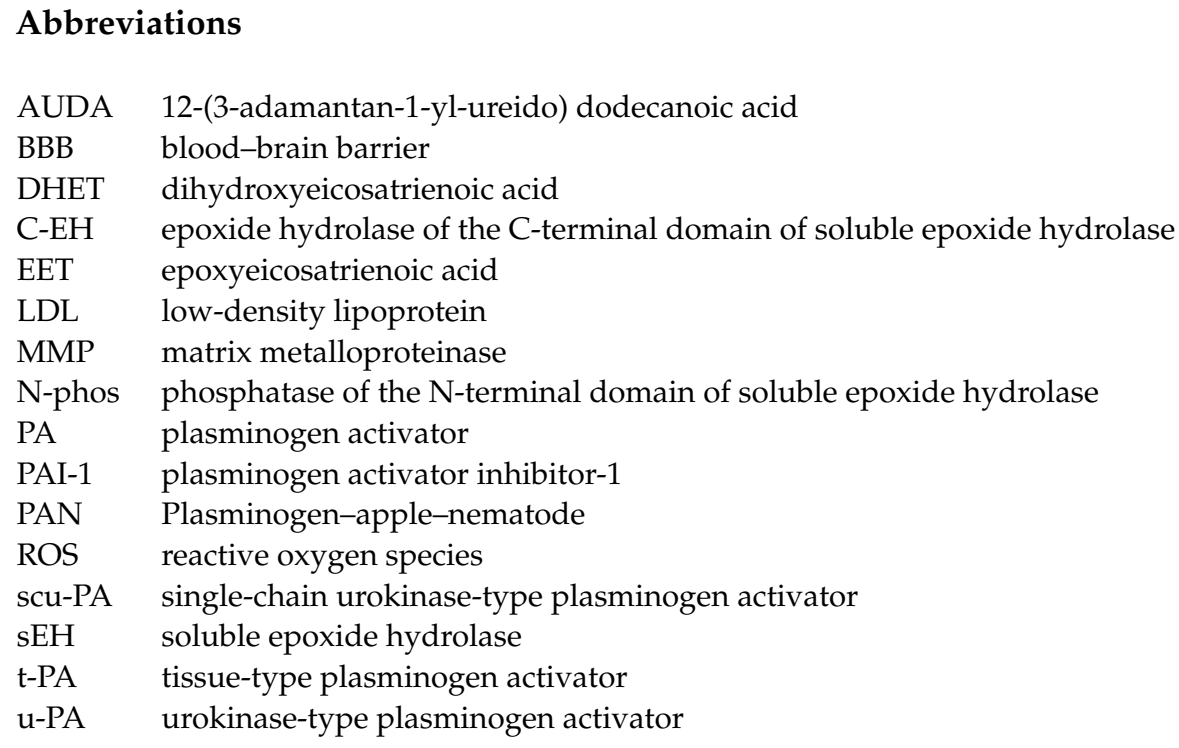

\section{References}

1. Versteeg, H.H.; Heemskerk, J.W.M.; Levi, M.; Reitsma, P.H. New Fundamentals in hemostasis. Physiol. Rev. 2013, 93, 327-358. [CrossRef] [PubMed]

2. Smith, S.A.; Travers, R.J.; Morrissey, J.H. How it all starts: Initiation of the clotting cascade. Crit. Rev. Biochem. Mol. Biol. 2015, 50, 326-336. [CrossRef]

3. Chapin, J.C.; Hajjar, K.A. Fibrinolysis and the control of blood coagulation. Blood Rev. 2015, 29, 17-24. [CrossRef] [PubMed]

4. Hasumi, K.; Yamamichi, S.; Harada, T. Small-molecule modulators of zymogen activation in the fibrinolytic and coagulation systems: Review Article. FEBS J. 2010, 277. [CrossRef] [PubMed]

5. Urano, T.; Castellino, F.J.; Suzuki, Y. Regulation of plasminogen activation on cell surfaces and fibrin. J. Thromb. Haemost. 2018, 16, 1487-1497. [CrossRef] [PubMed]

6. Peyvandi, F.; Garagiola, I.; Biguzzi, E. Advances in the treatment of bleeding disorders. J. Thromb. Haemost. 2016, 14, 2095-2106 [CrossRef]

7. Kolev, K.; Longstaff, C. Bleeding related to disturbed fibrinolysis. Br. J. Haematol. 2016, 175, 12-23. [CrossRef]

8. Chang, Y.; Dabiri, G.; Damstetter, E.; Baiyee Ebot, E.; Powers, J.G.; Phillips, T. Coagulation disorders and their cutaneous presentations: Pathophysiology. J. Am. Acad. Dermatol. 2016, 74, 783-792. [CrossRef]

9. Hoffman, M.; Pawlinski, R. Hemostasis: Old system, new players, new directions. Thromb. Res. 2014, 133. [CrossRef]

10. Mega, J.L.; Simon, T. Pharmacology of antithrombotic drugs: An assessment of oral antiplatelet and anticoagulant treatments. Lancet 2015, 386, 281-291. [CrossRef]

11. McFadyen, J.D.; Peter, K. Novel Antithrombotic Drugs on the Horizon. Circ. Res. 2017, 121, 1133-1135. [CrossRef] [PubMed]

12. Bivard, A.; Lin, L.; Parsonsb, M.W. Review of Stroke Thrombolytics. J. Stroke 2013, 15, 90. [CrossRef] [PubMed]

13. Martin, C.; Sobolewski, K.; Bridgeman, P.; Boutsikaris, D. Systemic thrombolysis for pulmonary embolism: A review. Pharm. Ther. 2016, 41, 770-775.

14. Ibrahim, H.; Rondina, M.; Welt, F.G.P. Antithrombotic drugs in cardiovascular medicine: A year in review. Curr. Opin. Cardiol. 2018, 33, 369-374. [CrossRef] [PubMed]

15. Goldstein, J.N.; Marrero, M.; Masrur, S.; Pervez, M.; Barrocas, A.M.; Abdullah, A.; Oleinik, A.; Rosand, J.; Smith, E.E.; Dzik, W.H.; et al. Management of thrombolysis-associated symptomatic intracerebral hemorrhage. Arch. Neurol. 2010, 67, 965-969. [CrossRef]

16. Piran, S.; Schulman, S. Treatment of bleeding complications in patients on anticoagulant therapy. Blood 2019, 133, 425-435. [CrossRef]

17. De Andrade, N.K.; Motta, R.H.L.; Bergamaschi, C.D.C.; Oliveira, L.B.; Guimarães, C.C.; Araújo, J.D.O.; Lopes, L.C. Bleeding risk in patients using oral anticoagulants undergoing surgical procedures in dentistry: A systematic review and meta-analysis. Front. Pharmacol. 2019, 10. [CrossRef]

18. Macman, N. Triggers, targets and treatments for thrombosis. Nature 2008, 451, 914-918. [CrossRef]

19. Hu, W.; Narasaki, R.; Nishimura, N.; Hasumi, K. SMTP (Stachybotrys microspora triprenyl phenol) enhances clot clearance in a pulmonary embolism model in rats. Thromb. J. 2012, 10. [CrossRef]

20. Matsumoto, N.; Suzuki, E.; Tsujihara, K.; Nishimura, Y.; Hasumi, K. Structure-activity relationships of the plasminogen modulator SMTP with respect to the inhibition of soluble epoxide hydrolase. J. Antibiot. (Tokyo) 2015, 68, 685-690. [CrossRef]

21. Shibata, K.; Hashimoto, T.; Nobe, K.; Hasumi, K.; Honda, K. A novel finding of a low-molecular-weight compound, SMTP-7, having thrombolytic and anti-inflammatory effects in cerebral infarction of mice. Naunyn. Schmiedebergs. Arch. Pharmacol. 2010, 382. [CrossRef] [PubMed] 
22. Sawada, H.; Nishimura, N.; Suzuki, E.; Zhuang, J.; Hasegawa, K.; Takamatsu, H.; Honda, K.; Hasumi, K. SMTP-7, a novel small-molecule thrombolytic for ischemic stroke: A study in rodents and primates. J. Cereb. Blood Flow Metab. 2014, 34. [CrossRef] [PubMed]

23. Ito, A.; Niizuma, K.; Shimizu, H.; Fujimura, M.; Hasumi, K.; Tominaga, T. SMTP-7, a new thrombolytic agent, decreases hemorrhagic transformation after transient middle cerebral artery occlusion under warfarin anticoagulation in mice. Brain Res. 2014, 1578. [CrossRef] [PubMed]

24. Huang, Y.; Ohta, Y.; Shang, J.; Li, X.; Liu, X.; Shi, X.; Feng, T.; Yamashita, T.; Sato, K.; Takemoto, M.; et al. Reduction of Ischemia Reperfusion-Related Brain Hemorrhage by Stachybotrys Microspora Triprenyl Phenol-7 in Mice With Antioxidant Effects. J. Stroke Cerebrovasc. Dis. 2018, 27. [CrossRef] [PubMed]

25. Matsumoto, N.; Suzuki, E.; Ishikawa, M.; Shirafuji, T.; Hasumi, K. Soluble epoxide hydrolase as an anti-inflammatory target of the thrombolytic stroke drug SMTP-7. J. Biol. Chem. 2014, 289, 35826-35838. [CrossRef]

26. Hashimoto, T.; Shibata, K.; Nobe, K.; Hasumi, K.; Honda, K. A novel embolic model of cerebral infarction and evaluation of Stachybotrys microspora triprenyl phenol-7 (SMTP-7), a novel fungal triprenyl phenol metabolite. J. Pharmacol. Sci. 2010, 114. [CrossRef]

27. Akamatsu, Y.; Saito, A.; Fujimura, M.; Shimizu, H.; Mekawy, M.; Hasumi, K.; Tominaga, T. Stachybotrys microspora triprenyl phenol-7, a novel fibrinolytic agent, suppresses superoxide production, matrix metalloproteinase-9 expression, and thereby attenuates ischemia/reperfusion injury in rat brain. Neurosci. Lett. 2011, 503. [CrossRef]

28. Suzuki, E.; Nishimura, N.; Yoshikawa, T.; Kunikiyo, Y.; Hasegawa, K.; Hasumi, K. Efficacy of SMTP-7, a small-molecule anti-inflammatory thrombolytic, in embolic stroke in monkeys. Pharmacol. Res. Perspect. 2018, 6. [CrossRef]

29. Shibata, K.; Hashimoto, T.; Hasumi, K.; Honda, K.; Nobe, K. Evaluation of the effects of a new series of SMTPs in the acetic acid-induced embolic cerebral infarct mouse model. Eur. J. Pharmacol. 2018, 818. [CrossRef]

30. Shi, X.; Ohta, Y.; Shang, J.; Morihara, R.; Nakano, Y.; Fukui, Y.; Liu, X.; Feng, T.; Huang, Y.; Sato, K.; et al. Neuroprotective effects of SMTP-44D in mice stroke model in relation to neurovascular unit and trophic coupling. J. Neurosci. Res. 2018, 96. [CrossRef]

31. Cushman, M. Epidemiology and Risk Factors for Venous Thrombosis. Semin. Hematol. 2007, 44, 62-69. [CrossRef]

32. Previtali, E.; Bucciarelli, P.; Passamonti, S.M.; Martinelli, I. Risk factors for venous and arterial thrombosis. Blood Transfus. 2011, 9 , 120-138. [CrossRef]

33. Badimon, L.; Vilahur, G. Thrombosis formation on atherosclerotic lesions and plaque rupture. J. Intern. Med. 2014, 276, 618-632. [CrossRef]

34. Otsuka, F.; Yasuda, S.; Noguchi, T.; Ishibashi-Ueda, H. Pathology of coronary atherosclerosis and thrombosis. Cardiovasc. Diagn. Ther. 2016, 6, 396-408. [CrossRef]

35. Rijken, D.C.; Lijnen, H.R. New insights into the molecular mechanisms of the fibrinolytic system. J. Thromb. Haemost. 2009, 7, 4-13. [CrossRef]

36. Majithia, A.; Bhatt, D.L. Novel Antiplatelet Therapies for Atherothrombotic Diseases. Arterioscler. Thromb. Vasc. Biol. 2019, 39, 546-557. [CrossRef] [PubMed]

37. Nakamura, M.; Yamada, N.; Ito, M. Novel Anticoagulant Therapy of Venous Thromboembolism: Current Status and Future Directions. Ann. Vasc. Dis. 2017, 10, 92-98. [CrossRef] [PubMed]

38. Eikelboom, J.W.; Connolly, S.J.; Bosch, J.; Dagenais, G.R.; Hart, R.G.; Shestakovska, O.; Diaz, R.; Alings, M.; Lonn, E.M.; Anand, S.S.; et al. Rivaroxaban with or without aspirin in stable cardiovascular disease. N. Engl. J. Med. 2017, 377, 1319-1330. [CrossRef] [PubMed]

39. Steffel, J.; Eikelboom, J.W.; Anand, S.S.; Shestakovska, O.; Yusuf, S.; Fox, K.A.A. The COMPASS Trial. Circulation 2020, 142, 40-48. [CrossRef] [PubMed]

40. Miller, D.J.; Simpson, J.R.; Silver, B.; Silver, B. Safety of Thrombolysis in Acute Ischemic Stroke: A Review of Complications, Risk Factors, and Newer Technologies. Neurohospitalist 2011, 1, 138-147. [CrossRef] [PubMed]

41. Demaerschalk, B.M.; Cheng, N.T.; Kim, A.S. Intravenous Thrombolysis for Acute Ischemic Stroke Within 3 Hours Versus Between 3 and 4.5 Hours of Symptom Onset. Neurohospitalist 2015, 5, 101-109. [CrossRef]

42. Endo, A. A historical perspective on the discovery of statins. Proc. Jpn. Acad. Ser. B Phys. Biol. Sci. 2010, 86, 484-493. [CrossRef] [PubMed]

43. Hajar, R. Statins: Past and Present. Hear. Views 2011, 12, 121. [CrossRef]

44. Anglés-Cano, E. Overview on fibrinolysis: Plasminogen activation pathways on fibrin and cell surfaces. Chem. Phys. Lipids 1994, 67-68, 353-362. [CrossRef]

45. McLean, J.W.; Tomlinson, J.E.; Kuang, W.J.; Eaton, D.L.; Chen, E.Y.; Fless, G.M.; Scanu, A.M.; Lawn, R.M. cDNA sequence of human apolipoprotein(a) is homologous to plasminogen. Nature 1987, 330, 132-137. [CrossRef] [PubMed]

46. Hajjar, K.A.; Gavishi, D.; Breslow, J.L.; Nachman, R.L. Lipoprotein(a) modulation of endothelial cell surface fibrinolysis and its potential role in atherosclerosis. Nature 1989, 339, 303-305. [CrossRef]

47. Tachikawa, K.; Hasumi, K.; Endo, A. Enhancement of plasminogen binding to U937 cells and fibrin by complestatin. Thromb. Haemost. 1997, 77. [CrossRef]

48. Tachikawa, K.; Hasumi, K.; Endo, A. Enhancement of plasminogen binding and fibrinolysis by chloropeptin I. Thromb. Res. 1997, 87. [CrossRef] 
49. Shinohara, C.; Hasumi, K.; Hatsumi, W.; Endo, A. Staplabin, a novel fungal triprenyl phenol which stimulates the binding of plasminogen to fibrin and U937 cells. J. Antibiot. (Tokyo) 1996, 49. [CrossRef]

50. Kohyama, T.; Hasumi, K.; Hamanaka, A.; Endo, A. SMTP-1 and -2, novel analogs of staplabin produced by Stachybotrys microspora IFO30018. J. Antibiot. (Tokyo) 1997, 50. [CrossRef]

51. Hasumi, K.; Ohyama, S.; Kohyama, T.; Ohsaki, Y.; Takayasu, R.; Endo, A. Isolation of SMTP-3, 4, 5 and -6, novel analogs of staplabin, and their effects on plasminogen activation and fibrinolysis. J. Antibiot. (Tokyo) 1998, 51. [CrossRef] [PubMed]

52. Hu, W.; Ohyama, S.; Hasumi, K. Activation of fibrinolysis by SMTP-7 and -8, novel staplabin analogs with a pseudosymmetric structure. J. Antibiot. (Tokyo) 2000, 53. [CrossRef] [PubMed]

53. Hu, W.; Narasaki, R.; Ohyama, S.; Hasumi, K. Selective production of staplabin and SMTPs in cultures of Stachybotrys microspora Fed with precursor amines. J. Antibiot. (Tokyo) 2001, 54. [CrossRef]

54. Hu, W.; Kitano, Y.; Hasumi, K. SMTP-4D, -5D, -7D and -8D, a new series of the non-lysine-analog plasminogen modulators with a D-amino acid moiety. J. Antibiot. (Tokyo) 2003, 56. [CrossRef] [PubMed]

55. Hasumi, K.; Hasegawa, K.; Kitano, Y. Isolation and absolute configuration of SMTP-0, a simplest congener of the SMTP family nonlysine-analog plasminogen modulators. J. Antibiot. (Tokyo) 2007, 60. [CrossRef] [PubMed]

56. Hasegawa, K.; Koide, H.; Hu, W.; Nishimura, N.; Narasaki, R.; Kitano, Y.; Hasumi, K. Structure-activity relationships of 11 new congeners of the SMTP plasminogen modulator. J. Antibiot. (Tokyo) 2010, 63. [CrossRef]

57. Koide, H.; Hasegawa, K.; Nishimura, N.; Narasaki, R.; Hasumi, K. A new series of the SMTP plasminogen modulators with a phenylamine-based side chain. J. Antibiot. (Tokyo) 2012, 65. [CrossRef]

58. Koide, H.; Narasaki, R.; Hasegawa, K.; Nishimura, N.; Hasumi, K. A new series of the SMTP plasminogen modulator with a phenylglycine-based side chain. J. Antibiot. (Tokyo) 2012, 65. [CrossRef]

59. Nishimura, Y.; Suzuki, E.; Hasegawa, K.; Nishimura, N.; Kitano, Y.; Hasumi, K. Pre-SMTP, a key precursor for the biosynthesis of the SMTP plasminogen modulators. J. Antibiot. (Tokyo) 2012, 65. [CrossRef] [PubMed]

60. Otake, S.; Ogawa, N.; Kitano, Y.; Hasumi, K.; Suzuki, E. Isoprene side-chain of SMTP is essential for soluble epoxide hydrolase inhibition and cellular localization. Nat. Prod. Commun. 2016, 11. [CrossRef]

61. Jacolot, M.; Jean, M.; Tumma, N.; Bondon, A.; Chandrasekhar, S.; Van De Weghe, P. Synthesis of stachybotrin C and all of its stereoisomers: Structure revision. J. Org. Chem. 2013, 78, 7169-7175. [CrossRef]

62. Kuroda, Y.; Hasegawa, K.; Noguchi, K.; Chiba, K.; Hasumi, K.; Kitano, Y. Confirmation of the absolute configuration of Stachybotrin C using single-crystal X-ray diffraction analysis of its 4-bromobenzyl ether derivative. J. Antibiot. (Tokyo) $2018,71$. [CrossRef] [PubMed]

63. Li, C.; Matsuda, Y.; Gao, H.; Hu, D.; Yao, X.S.; Abe, I. Biosynthesis of LL-Z1272ß: Discovery of a New Member of NRPS-like Enzymes for Aryl-Aldehyde Formation. ChemBioChem 2016, 17, 904-907. [CrossRef] [PubMed]

64. Semeiks, J.; Borek, D.; Otwinowski, Z.; Grishin, N.V. Comparative genome sequencing reveals chemotype-specific gene clusters in the toxigenic black mold Stachybotrys. BMC Genomics 2014, 15. [CrossRef] [PubMed]

65. Yin, Y.; Fu, Q.; Wu, W.; Cai, M.; Zhou, X.; Zhang, Y. Producing novel fibrinolytic isoindolinone derivatives in marine fungus Stachybotrys longispora FG216 by the rational supply of amino compounds according to its biosynthesis pathway. Mar. Drugs 2017, 15, 214. [CrossRef]

66. Ayer, W.A.; Miao, S. Secondary metabolites of the aspen fungus Stachybotrys cylindrospora. Can. J. Chem. 1993, 71, 487-493. [CrossRef]

67. Alajarín, M.; Sánchez-Andrada, P.; López-Leonardo, C.; Álvarez, Á. On the mechanism of phthalimidine formation via ophthalaldehyde monoimines. New [1,5]-H sigmatropic rearrangements in molecules with the 5-aza-2,4-pentadienal skeleton. J. Org. Chem. 2005, 70, 7617-7623. [CrossRef]

68. Gyimesi-Forrás, K.; Leitner, A.; Akasaka, K.; Lindner, W. Comparative study on the use of ortho-phthalaldehyde, naphthalene-2,3dicarboxaldehyde and anthracene-2,3-dicarboxaldehyde reagents for $\alpha$-amino acids followed by the enantiomer separation of the formed isoindolin-1-one derivatives using quinine-type chir. J. Chromatogr. A 2005, 1083, 80-88. [CrossRef]

69. Kawano, Y. Development of a Novel PAI-1 Inhibitor Using Beta-SMTP. Master's Thesis, Tokyo University of Agriculture and Technology, Tokyo, Japan, March 2010.

70. Takahashi, F.; Hasumi, K.; Endo, A. Modulation of the plasma cholesteryl ester transfer by stachybotramide. Biochim. Biophys. Acta (BBA)/Lipids Lipid Metab. 1995, 1258, 70-74. [CrossRef]

71. Wang, A.; Xu, Y.; Gao, Y.; Huang, Q.; Luo, X.; An, H.; Dong, J. Chemical and bioactive diversities of the genera Stachybotrys and Memnoniella secondary metabolites. Phytochem. Rev. 2015, 14, 623-655. [CrossRef]

72. Miyazaki, W.; Izawa, T.; Nakano, Y.; Shinohara, M.; Hing, K.; Kinoshita, T.; Inoue, K. Effects of K-76 monocarboxylic acid, an anticomplementary agent, on various in vivo immunological reactions and on experimental glomerulonephritis. Complement 1984, 1, 134-146. [CrossRef] [PubMed]

73. Sawadjoon, S.; Kittakoop, P.; Isaka, M.; Kirtikara, K.; Madla, S.; Thebtaranonth, Y. Antiviral and antiplasmodial spirodihydrobenzofuran terpenes from the fungus Stachybotrys nephrospora. Planta Med. 2004, 70, 1085-1087. [CrossRef] [PubMed]

74. Kaneto, R.; Dobashi, K.; Kojima, I.; Sakai, K.; Shibamoto, N.; Yoshioka, T.; Nishida, H.; Okamoto, R.; Akagawa, H.; Mizuno, S. Mer-NF5003B, E and F, novel sesquiterpenoids as avian myeloblastosis virus protease inhibitors produced by Stachybotrys sp. J. Antibiot. (Tokyo) 1994, 47, 727-730. [CrossRef] [PubMed] 
75. Lam, Y.K.T.; Wichmann, C.F.; Meinz, M.S.; Guariglia, L.; Glacobbe, R.A.; Mochales, S.; Kong, L.; Honeycutt, S.S.; Zlnk, D.; Bills, G.F.; et al. A novel inositol mono-phosphatase inhibitor from Memnoniella echinata: Producing organism, fermentation, isolation, physico-chemical and in vitro biological properties. J. Antibiot. (Tokyo) 1992, 45, 1397-1402. [CrossRef]

76. Lin, T.W.; Chang, W.W.; Chen, C.C.; Tsai, Y.C. Stachybotrydial, a potent inhibitor of fucosyltransferase and sialyltransferase. Biochem. Biophys. Res. Commun. 2005, 331, 953-957. [CrossRef]

77. Sakai, K.; Watanabe, K.; Masuda, K.; Tsuji, M.; Hasumi, K.; Endo, A. Isolation, Characterization and Biological Activities of Novel Triprenyl Phenols as Pancreatic Cholesterol Esterase Inhibitors Produced by Stachybotrys sp. F-1839. J. Antibiot. (Tokyo) 1995, 48, 447-456. [CrossRef]

78. Nakamura, M.; Ito, Y.; Ogawa, K.; Michisuji, Y.; Sato, S.I.; Takada, M.; Hayashi, M.; Yaginuma, S.; Yamamoto, S. Stachybocins, Novel Endothelin Receptor Antagonists, Produced by Stachybotrys sp. M6222: I. Taxonomy, Fermentation, Isolation and Characterization. J. Antibiot. (Tokyo) 1995, 48, 1389-1395. [CrossRef]

79. Vázquez, M.J.; Vega, A.; Rivera-Sagredo, A.; Jiménez-Alfaro, M.D.; Díez, E.; Hueso-Rodríguez, J.A. Novel sesquiterpenoids as tyrosine kinase inhibitors produced by Stachybotrys chortarum. Tetrahedron 2004, 60, 2379-2385. [CrossRef]

80. Vértesy, L.; Kogler, H.; Markus, A.; Schiell, M.; Vogel, M.; Wink, J. Memnopeptide A, a novel terpene peptide from Memnoniella with an activating effect on SERCA2. J. Antibiot. (Tokyo) 2001, 54, 771-782. [CrossRef]

81. Li, Y.; Wu, C.; Liu, D.; Proksch, P.; Guo, P.; Lin, W. Chartarlactams A-P, phenylspirodrimanes from the sponge-associated fungus stachybotrys chartarum with antihyperlipidemic activities. J. Nat. Prod. 2014, 77, 138-147. [CrossRef]

82. Ma, X.; Li, L.; Zhu, T.; Ba, M.; Li, G.; Gu, Q.; Guo, Y.; Li, D. Phenylspirodrimanes with anti-HIV activity from the sponge-derived fungus Stachybotrys chartarum mxh-x73. J. Nat. Prod. 2013, 76, 2298-2306. [CrossRef]

83. Wu, B.; Oesker, V.; Wiese, J.; Malien, S.; Schmaljohann, R.; Imhoff, J.F. Spirocyclic drimanes from the marine fungus Stachybotrys sp. strain MF347. Mar. Drugs 2014, 12, 1924-1938. [CrossRef] [PubMed]

84. Xu, X.; de Guzman, F.S.; Gloer, J.B.; Shearer, C.A. Stachybotrins A and B: Novel Bioactive Metabolites from a Brackish Water Isolate of the Fungus Stachybotrys sp. J. Org. Chem. 1992, 57, 6700-6703. [CrossRef]

85. Nozawa, Y.; Yamamoto, K.; Ito, M.; Sakai, N.; Mizoue, K.; Mizobe, F.; Hanada, K. Stachybotrin C and parvisporin, novel neuritogenic compounds. I. Taxonomy, isolation, physico-chemical and biological properties. J. Antibiot. (Tokyo) 1997, 50, 635-640. [CrossRef] [PubMed]

86. Singh, S.B.; Zink, D.L.; Williams, M.; Polishook, J.D.; Sanchez, M.; Silverman, K.C.; Lingham, R.B. Kampanols: Novel Ras farnesyl-protein transferase inhibitors from Stachybotrys kampalensis. Bioorganic Med. Chem. Lett. 1998, 8, 2071-2076. [CrossRef]

87. Minagawa, K.; Kouzuki, S.; Nomura, K.; Yamaguchi, T.; Kawamura, Y.; Matsushima, K.; Tani, H.; Ishii, K.; Tanimoto, T.; Kamigauchi, T. Bisabosquals, novel squalene synthase inhibitors. I. Taxonomy, fermentation, isolation and biological activities. J. Antibiot. (Tokyo) 2001, 54, 890-895. [CrossRef] [PubMed]

88. Minagawa, K.; Kouzuki, S.; Yoshimoto, J.; Kawamura, Y.; Tani, H.; Iwata, T.; Terui, Y.; Nakai, H.; Yagi, S.; Hattori, N.; et al. Stachyflin and acetylstachyflin, novel anti-influenza A virus substances, produced by Stachybotrys sp. RF-7260. I. Isolation, structure elucidation and biological activities. J. Antibiot. (Tokyo) 2002, 55, 155-164. [CrossRef]

89. Sasaoka, M.; Wada, Y.; Hasumi, K. Stachybotrydial selectively enhances fibrin binding and activation of Glu-plasminogen. J. Antibiot. (Tokyo) 2007, 60. [CrossRef]

90. Takayasu, R.; Hasumi, K.; Shinohara, C.; Endo, A. Enhancement of fibrin binding and activation of plasminogen by staplabin through induction of a conformational change in plasminogen. FEBS Lett. 1997, 418. [CrossRef]

91. Christensen, U. The AH-site of plasminogen and two C-terminal fragments. A weak lysine-binding site preferring ligands not carrying a free carboxylate function. Biochem. J. 1984, 223, 413-421. [CrossRef]

92. Cockell, C.S.; Marshall, J.M.; Dawson, K.M.; Cederholm-Williams, S.A.; Ponting, C.P. Evidence that the conformation of unliganded human plasminogen is maintained via an intramolecular interaction between the lysine-binding site of kringle 5 and the N-terminal peptide. Biochem. J. 1998, 333, 99-105. [CrossRef] [PubMed]

93. An, S.S.A.; Carreño, C.; Marti, D.N.; Schaller, J.; Albericio, F.; Llinas, M. Lysine-50 is a likely site for anchoring the plasminogen N-terminal peptide to lysine-binding kringles. Protein Sci. 1998, 7, 1960-1969. [CrossRef] [PubMed]

94. Law, R.H.P.; Caradoc-Davies, T.; Cowieson, N.; Horvath, A.J.; Quek, A.J.; Encarnacao, J.A.; Steer, D.; Cowan, A.; Zhang, Q.; Lu, B.G.C.; et al. The X-ray Crystal Structure of Full-Length Human Plasminogen. Cell Rep. 2012, 1, 185-190. [CrossRef] [PubMed]

95. Xue, Y.; Bodin, C.; Olsson, K. Crystal structure of the native plasminogen reveals an activation-resistant compact conformation. J. Thromb. Haemost. 2012, 10, 1385-1396. [CrossRef] [PubMed]

96. Medved, L.; Nieuwenhuizen, W. Molecular mechanisms of initiation of fibrinolysis by fibrin. Thromb. Haemost. 2003, 89, 409-419. [CrossRef] [PubMed]

97. Koyanagi, K.; Narasaki, R.; Yamamichi, S.; Suzuki, E.; Hasumi, K. Mechanism of the action of SMTP-7, a novel small-molecule modulator of plasminogen activation. Blood Coagul. Fibrinolysis 2014, 25. [CrossRef]

98. Battistel, M.D.; Grishaev, A.; An, S.S.A.; Castellino, F.J.; Lliná, M. Solution structure and functional characterization of human plasminogen kringle 5. Biochemistry 2009, 48, 10208-10219. [CrossRef]

99. Thorsen, S. The Mechanism of Plasminogen Activation and the Variability of the Fibrin Effector during Tissue-type Plasminogen Activator-Mediated Fibrinolysis. Ann. N. Y. Acad. Sci. 1992, 667, 52-63. [CrossRef]

100. Ohyama, S.; Wada, Y.; Hasumi, K. Antibiotic A10255 (Thioplabin) enchances fibrin binding and activation of plasminogen. J. Antibiot. (Tokyo) 2002, 55. [CrossRef] 
101. Ohyama, S.; Harada, T.; Chikanishi, T.; Miura, Y.; Hasumi, K. Nonlysine-analog plasmmogen modulators promote autoproteolytic generation of plasmin(ogen) fragments with angiostatin-like activity. Eur. J. Biochem. 2004, 271. [CrossRef]

102. Kikuchi, T.; Hasumi, K. Enhancement of plasminogen activation by surfactin C: Augmentation of fibrinolysis in vitro and in vivo. Biochim. Biophys. Acta Protein Struct. Mol. Enzymol. 2002, 1596. [CrossRef]

103. Kikuchi, T.; Hasumi, K. Enhancement of reciprocal activation of prourokinase and plasminogen by the bacterial lipopeptide surfactins and iturin Cs. J. Antibiot. (Tokyo) 2003, 56. [CrossRef]

104. Wu, W.; Narasaki, R.; Maeda, F.; Hasumi, K. Glucosyldiacylglycerol enhances reciprocal activation of prourokinase and plasminogen. Biosci. Biotechnol. Biochem. 2004, 68. [CrossRef] [PubMed]

105. Inoue, T.; Hasumi, K.; Kuniyasu, T.; Endo, A. Isolation of plactins A, B, C and D, novel cyclic pentapeptides that stimulate cellular fibrinolytic activity. J. Antibiot. (Tokyo) 1996, 49. [CrossRef] [PubMed]

106. Inoue, T.; Hasumi, K.; Sugimoto, M.; Endo, A. Enhancement of fibrinolysis by plactins: Structure-activity relationship and effects in human U937 cells and in mice. Thromb. Haemost. 1998, 79. [CrossRef]

107. Harada, T.; Tsuruta, T.; Yamagata, K.; Inoue, T.; Hasumi, K. Dual modulation of prothrombin activation by the cyclopentapeptide plactin. FEBS J. 2009, 276. [CrossRef] [PubMed]

108. Yamamoto, E.; Yamamichi, S.; Choi-Miura, N.-H.; Hasumi, K. The cyclopentapeptide plactin enhances cellular binding and autoactivation of the serine protease plasma hyaluronan-binding protein. Thromb. Res. 2010, 126. [CrossRef] [PubMed]

109. Hu, W. Novel Fungal Triprenyl Phenols That Enhance Fibrinolysis and Suppress Tumor Growth. Ph.D. Thesis, Tokyo University of Agriculture and Technology, Tokyo, Japan, March 2003.

110. Lund, L.R.; Green, K.A.; Stoop, A.A.; Ploug, M.; Almholt, K.; Lilla, J.; Nielsen, B.S.; Christensen, I.J.; Craik, C.S.; Werb, Z.; et al. Plasminogen activation independent of uPA and tPA maintains wound healing in gene-deficient mice. EMBO J. 2006, 25, 2686-2697. [CrossRef]

111. Danø, K.; Behrendt, N.; Høyer-Hansen, G.; Johnsen, M.; Lund, L.R.; Ploug, M.; Rømer, J. Plasminogen activation and cancer. Thromb. Haemost. 2005, 93, 676-681. [CrossRef]

112. Castellino, F.J.; Ploplis, V.A. Structure and function of the plasminogen/plasmin system. Thromb. Haemost. 2005, 93, 647-654. [CrossRef]

113. Harris, T.R.; Hammock, B.D. Soluble epoxide hydrolase: Gene structure, expression and deletion. Gene 2013, 526, 61-74. [CrossRef] [PubMed]

114. Spector, A.A.; Fang, X.; Snyder, G.D.; Weintraub, N.L. Epoxyeicosatrienoic acids (EETs): Metabolism and biochemical function. Prog. Lipid Res. 2004, 43, 55-90. [CrossRef]

115. Morisseau, C.; Hammock, B.D. Impact of Soluble Epoxide Hydrolase and Epoxyeicosanoids on Human Health. Annu. Rev. Pharmacol. Toxicol. 2013, 53, 37-58. [CrossRef] [PubMed]

116. Wagner, K.M.; McReynolds, C.B.; Schmidt, W.K.; Hammock, B.D. Soluble epoxide hydrolase as a therapeutic target for pain, inflammatory and neurodegenerative diseases. Pharmacol. Ther. 2017, 180, 62-76. [CrossRef] [PubMed]

117. Hashimoto, K. Role of soluble epoxide hydrolase in metabolism of PUFAs in psychiatric and neurological disorders. Front. Pharmacol. 2019, 9. [CrossRef]

118. Oguro, A.; Imaoka, S. Lysophosphatidic acids are new substrates for the phosphatase domain of soluble epoxide hydrolase. J. Lipid Res. 2012, 53, 505-512. [CrossRef]

119. Morisseau, C.; Schebb, N.H.; Dong, H.; Ulu, A.; Aronov, P.A.; Hammock, B.D. Role of soluble epoxide hydrolase phosphatase activity in the metabolism of lysophosphatidic acids. Biochem. Biophys. Res. Commun. 2012, 419, 796-800. [CrossRef] [PubMed]

120. Kramer, J.; Proschak, E. Phosphatase activity of soluble epoxide hydrolase. Prostaglandins Other Lipid Mediat. 2017, 133, 88-92. [CrossRef] [PubMed]

121. Luria, A.; Bettaieb, A.; Xi, Y.; Shieh, G.J.; Liu, H.C.; Inoue, H.; Tsai, H.J.; Imig, J.D.; Haj, F.G.; Hammock, B.D. Soluble epoxide hydrolase deficiency alters pancreatic islet size and improves glucose homeostasis in a model of insulin resistance. Proc. Natl. Acad. Sci. USA 2011, 108, 9038-9043. [CrossRef] [PubMed]

122. Liu, J.Y. Inhibition of soluble epoxide hydrolase for renal health. Front. Pharmacol. 2019, 9. [CrossRef]

123. Ren, Q. Soluble epoxide hydrolase inhibitor: A novel potential therapeutic or prophylactic drug for psychiatric disorders. Front. Pharmacol. 2019, 10. [CrossRef] [PubMed]

124. Hung, T.H.; Shyue, S.K.; Wu, C.H.; Chen, C.C.; Lin, C.C.; Chang, C.F.; Chen, S.F. Deletion or inhibition of soluble epoxide hydrolase protects against brain damage and reduces microglia-mediated neuroinflammation in traumatic brain injury. Oncotarget 2017, 8, 103236-103260. [CrossRef] [PubMed]

125. Li, D.; Liu, Y.; Zhang, X.; Lv, H.; Pang, W.; Sun, X.; Gan, L.M.; Hammock, B.D.; Ai, D.; Zhu, Y. Inhibition of soluble epoxide hydrolase alleviated atherosclerosis by reducing monocyte infiltration in Ldlr-/- mice. J. Mol. Cell. Cardiol. 2016, 98, 128-137. [CrossRef] [PubMed]

126. Zhang, W.; Koerner, I.P.; Noppens, R.; Grafe, M.; Tsai, H.J.; Morisseau, C.; Luria, A.; Hammock, B.D.; Falck, J.R.; Alkayed, N.J. Soluble epoxide hydrolase: A novel therapeutic target in stroke. J. Cereb. Blood Flow Metab. 2007, 27, 1931-1940. [CrossRef]

127. Zhang, W.; Otsuka, T.; Sugo, N.; Ardeshiri, A.; Alhadid, Y.K.; Iliff, J.J.; DeBarber, A.E.; Koop, D.R.; Alkayed, N.J. Soluble epoxide hydrolase gene deletion is protective against experimental cerebral ischemia. Stroke 2008, 39, 2073-2078. [CrossRef] 
128. Chang, L.H.; Lin, H.C.; Huang, S.S.; Chen, I.C.; Chu, K.W.; Chih, C.L.; Liang, Y.W.; Lee, Y.C.; Chen, Y.Y.; Lee, Y.H.; et al. Blockade of soluble epoxide hydrolase attenuates post-ischemic neuronal hyperexcitation and confers resilience against stroke with TrkB activation. Sci. Rep. 2018, 8. [CrossRef]

129. Liu, Y.; Dang, H.; Li, D.; Pang, W.; Hammock, B.D.; Zhu, Y. Inhibition of soluble epoxide hydrolase attenuates high-fat-dietinduced hepatic steatosis by reduced systemic inflammatory status in mice. PLoS ONE 2012, 7. [CrossRef]

130. Zhang, W.; Yang, A.L.; Liao, J.; Li, H.; Dong, H.; Chung, Y.T.; Bai, H.; Matkowskyj, K.A.; Hammock, B.D.; Yang, G.Y. Soluble epoxide hydrolase gene deficiency or inhibition attenuates chronic active inflammatory bowel disease in IL-10(2/2) mice. Dig. Dis. Sci. 2012, 57, 2580-2591. [CrossRef]

131. Panigrahy, D.; Kalish, B.T.; Huang, S.; Bielenberg, D.R.; Le, H.D.; Yang, J.; Edin, M.L.; Lee, C.R.; Benny, O.; Mudge, D.K.; et al. Epoxyeicosanoids promote organ and tissue regeneration. Proc. Natl. Acad. Sci. USA 2013, 110, 13528-13533. [CrossRef]

132. Traber, M.G.; Atkinson, J. Vitamin E, antioxidant and nothing more. Free Radic. Biol. Med. 2007, 43, 4-15. [CrossRef]

133. Shibata, K.; Hashimoto, T.; Nobe, K.; Hasumi, K.; Honda, K. Neuroprotective mechanisms of SMTP-7 in cerebral infarction model in mice. Naunyn. Schmiedebergs. Arch. Pharmacol. 2011, 384. [CrossRef] [PubMed]

134. Feigin, V.L.; Krishnamurthi, R.V.; Parmar, P.; Norrving, B.; Mensah, G.; Bennett, D.A.; Barker-Collo, S.; Moran, A.E.; Sacco, R.L.; Truelsen, T.; et al. Update on the global burden of ischemic and hemorrhagic stroke in 1990-2013: The GBD 2013 study. Neuroepidemiology 2015, 45, 161-176. [CrossRef] [PubMed]

135. Katan, M.; Luft, A. Global Burden of Stroke. Semin. Neurol. 2018, 38, 208-211. [CrossRef] [PubMed]

136. Adams, H.P., Jr.; Bendixen, B.H.; Kappelle, L.J.; Biller, J.; Love, B.B.; Gordon, D.L.; Marsh, E.E., 3rd. Classification of subtype of acute ischemic stroke. Definitions for use in a multicenter clinical trial TOAST. Trial of Org 10172 in Acute Stroke Treatment. Stroke 1993, 24, 35-41. [CrossRef]

137. Arboix, A.; Alioc, J. Cardioembolic Stroke: Clinical Features, Specific Cardiac Disorders and Prognosis. Curr. Cardiol. Rev. 2010, 6, 150-161. [CrossRef] [PubMed]

138. Lund, R.W. Lacunar infarction, mortality over time and mortality relative to other ischemic strokes. J. Insur. Med. $2014,44,32-37$.

139. Kamel, H.; Healey, J.S. Cardioembolic Stroke. Circ. Res. 2017, 120, 514-526. [CrossRef]

140. Rothwell, P.M. Atherothrombosis and ischaemic stroke. Br. Med. J. 2007, 334, 379-380. [CrossRef]

141. Palomeras Soler, E.; Casado Ruiz, V. Epidemiology and Risk Factors of Cerebral Ischemia and Ischemic Heart Diseases: Similarities and Differences. Curr. Cardiol. Rev. 2010, 6, 138-149. [CrossRef]

142. Sacco, S.; Marini, C.; Totaro, R.; Russo, T.; Cerone, D.; Carolei, A. A population-based study of the incidence and prognosis of lacunar stroke. Neurology 2006, 66, 1335-1338. [CrossRef]

143. Lastilla, M. Lacunar infarct. Clin. Exp. Hypertens. 2006, 28, 205-215. [CrossRef] [PubMed]

144. Wardlaw, J.M.; Smith, C.; Dichgans, M. Mechanisms of sporadic cerebral small vessel disease: Insights from neuroimaging. Lancet Neurol. 2013, 12, 483-497. [CrossRef]

145. Guadagno, J.V.; Calautti, C.; Baron, J.C. Progress in imaging stroke: Emerging clinical applications. Br. Med. Bull. 2003, 65, 145-157. [CrossRef] [PubMed]

146. Cramer, S.C. Treatments to promote neural repair after stroke. J. Stroke 2018, 20, 57-70. [CrossRef]

147. Hassan, A. Recent Advances in the Management of Acute Ischemic Stroke; Springer: London, UK, 2010; pp. 61-68. [CrossRef]

148. Roesly, H. Thrombectomy for Stroke at 6 to 16 Hours with Selection by Perfusion Imaging. J. Emerg. Med. 2018, 55, 151. [CrossRef]

149. Nogueira, R.G.; Jadhav, A.P.; Haussen, D.C.; Bonafe, A.; Budzik, R.F.; Bhuva, P.; Yavagal, D.R.; Ribo, M.; Cognard, C.; Hanel, R.A.; et al. Thrombectomy 6 to $24 \mathrm{~h}$ after stroke with a mismatch between deficit and infarct. N. Engl. J. Med. 2018, 378, 11-21. [CrossRef]

150. Mican, J.; Toul, M.; Bednar, D.; Damborsky, J. Structural Biology and Protein Engineering of Thrombolytics. Comput. Struct. Biotechnol. J. 2019, 17, 917-938. [CrossRef]

151. Shibata, K.; Hashimoto, T.; Miyazaki, T.; Miyazaki, A.; Nobe, K. Thrombolytic Therapy for Acute Ischemic Stroke: Past and Future. Curr. Pharm. Des. 2019, 25, 242-250. [CrossRef]

152. Lin, H.; Xu, L.; Yu, S.; Hong, W.; Huang, M.; Xu, P. Therapeutics targeting the fibrinolytic system. Exp. Mol. Med. 2020, 52, 367-379. [CrossRef]

153. Dela Peña, I.; Borlongan, C.; Shen, G.; Davis, W. Strategies to extend thrombolytic time window for ischemic stroke treatment: An unmet clinical need. J. Stroke 2017, 19, 50-60. [CrossRef]

154. Bhogal, P.; Andersson, T.; Maus, V.; Mpotsaris, A.; Yeo, L. Mechanical Thrombectomy-A Brief Review of a Revolutionary new Treatment for Thromboembolic Stroke. Clin. Neuroradiol. 2018, 28, 313-326. [CrossRef] [PubMed]

155. Jadhav, A.P.; Desai, S.M.; Kenmuir, C.L.; Rocha, M.; Starr, M.T.; Molyneaux, B.J.; Gross, B.A.; Jankowitz, B.T.; Jovin, T.G. Eligibility for endovascular trial enrollment in the 6-to 24-hour time window analysis of a single comprehensive stroke center. Stroke 2018, 49, 1015-1017. [CrossRef] [PubMed]

156. Andrew Josephson, S.; Kamel, H. The acute stroke care revolution enhancing access to therapeutic advances. JAMA J. Am. Med. Assoc. 2018, 320, 1239-1240. [CrossRef] [PubMed]

157. Hashimoto, T.; Shibata, K.; Ohata, H.; Hasumi, K.; Honda, K. Altered gene expression in an embolic stroke model after thrombolysis with tissue plasminogen activator and Stachybotrys microspora triprenyl phenol-7. J. Pharmacol. Sci. 2014, 125. [CrossRef] 
158. Miyazaki, T.; Kimura, Y.; Ohata, H.; Hashimoto, T.; Shibata, K.; Hasumi, K.; Honda, K. Distinct effects of tissue-type plasminogen activator and SMTP-7 on cerebrovascular inflammation following thrombolytic reperfusion. Stroke 2011, 42. [CrossRef]

159. Huang, Y.; Ohta, Y.; Shang, J.; Morihara, R.; Nakano, Y.; Fukui, Y.; Liu, X.; Shi, X.; Feng, T.; Yamashita, T.; et al. Antineuroinflammatory Effect of SMTP-7 in Ischemic Mice. J. Stroke Cerebrovasc. Dis. 2018, 27. [CrossRef]

160. Verstraete, M.; Bounameaux, H.; de Cock, F.; Van de Werf, F.; Collen, D. Pharmacokinetics and systemic fibrinogenolytic effects of recombinant human tissue-type plasminogen activator (rt-PA) in humans. J. Pharmacol. Exp. Ther. 1985, 235, 506-512.

161. Verstraete, M.; Su, C.A.P.F.; Tanswell, P.; Feuerer, W.; Collen, D. Pharmacokinetics and effects on fibrinolytic and coagulation parameters of two doses of recombinant tissue-type plasminogen activator in healthy volunteers. Thromb. Haemost. 1986, 56, 1-5. [CrossRef]

162. Tanswell, P.; Seifried, E.; Su, P.C.A.F.; Feuerer, W.; Rijken, D.C. Pharmacokinetics and systemic effects of tissue-type plasminogen activator in normal subjects. Clin. Pharmacol. Ther. 1989, 46, 155-162. [CrossRef]

163. Jickling, G.C.; Liu, D.; Stamova, B.; Ander, B.P.; Zhan, X.; Lu, A.; Sharp, F.R. Hemorrhagic transformation after ischemic stroke in animals and humans. J. Cereb. Blood Flow Metab. 2014, 34, 185-199. [CrossRef]

164. Inoue, S.; Kim, R.; Hoshino, Y.; Honda, K. Synthesis of Tricyclic Pyrano[2,3-e]isoindolin-3-ones as the Core Structure of Stachybotrin A, B, and C. ChemInform 2006, 37. [CrossRef]

165. Tumma, N.; Jacolot, M.; Jean, M.; Chandrasekhar, S.; Van De Weghe, P. Synthetic studies towards stachybotrin C. Synlett 2012, 23, 2919-2922. [CrossRef] 